Resumen y traducción por el autor, José F. Nonidez

Universidad Columbia, Nueva York.

Los fenómenos meióticos en la espermatogénesis de Blaps, con especial mención del complejo $\mathrm{X}$.

El número de cromosomas es treinta y cinco, treinta de los cuales se fusionan por parejas durante la sinapsis originando quince bivalentes en el espermatocito primario. Los otros cinco cromosomas se reunen en un grupo, el complejo $\mathrm{X}$, durante la sinizesis temprana que tiene lugar cuando los cromosomas están aún en el estado de procromosomas. Los cromosomas del complejo $\mathrm{X}$ son de tamaño desigual; tres de ellos presentan forma de $\mathrm{V}$ y son mucho mayores que los restantes, que no pueden diferenciarse de los cromosomas ordinarios en las espermatogonias. Dos de los grandes cromosomas (denominados M-cromosomas) son homólogos, mientras que el tercero corresponde al cromosoma accesorio. Este último aparece condensado durante el periodo de crecimiento y a él están unidos los M-cromosomas y pequeños cromosomas del complejo. Los cromosomas de este último no se reunen en parejas durante la sinapsis, sino que permanecen en forma de filamentos independientes durante el periodo de crecimiento. El complejo X se disocia durante la primera mitosis de maduración. Uno de los M-cromosomas entra en uno de los espermatocitos secundarios, que recibe en total diez y seis cromosomas. El otro espermatocito recibe diez y nueve cromosomas, incluyendo los cuatro elementos restantes del complejo. El complejo X parece representar una condición intermedia entre los complejos formados exclusivamente por cromosomas sexuales y los originados por la asociación de un cromosoma sexual con un par de cromosomas ordinarios. 
AOTHOR'B ABETRACT OF THIS PAPER ISSOED

BY THE BIBLIOGRAPHIC SERVICE, APRIL 5

\title{
THE MEIOTIC PHENOMENA IN THE SPERMATOGEN- ESIS OF BLAPS, WITH SPECIAL REFERENCE TO THE X-COMPLEX
}

\author{
JOSE F. NONIDEZ \\ Department of Zoology, Columbia University \\ EIGHTY-SIX FIGURES \\ CON'TENTS
}

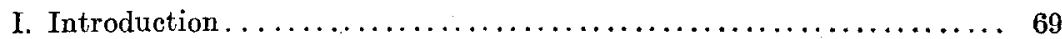

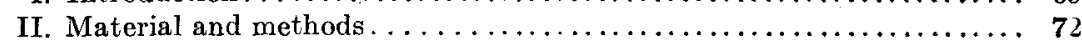

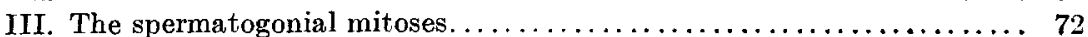

IV. The spermatocytes $\ldots \ldots \ldots \ldots \ldots \ldots \ldots \ldots \ldots \ldots \ldots \ldots \ldots \ldots \ldots \ldots \ldots$

1. The maturation mitoses $\ldots \ldots \ldots \ldots \ldots \ldots \ldots \ldots \ldots \ldots \ldots \ldots \ldots, 76$

A. First maturation mitosis . . . . . . . . . . . . . . . 76

B. The secondary spermatocytes and the second maturation

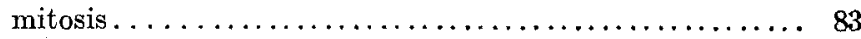

2. The growth period $\ldots \ldots \ldots \ldots \ldots \ldots \ldots \ldots \ldots \ldots \ldots \ldots \ldots \ldots . . \ldots 4$

A. Presynaptic stages and synapsis............... 85

B. Postsynaptic stages......................... 88

C. The X-complex during the growth period........... 89

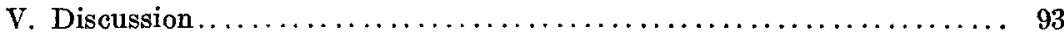

1. The growth period $\ldots \ldots \ldots \ldots \ldots \ldots \ldots \ldots \ldots \ldots \ldots \ldots \ldots, 93$

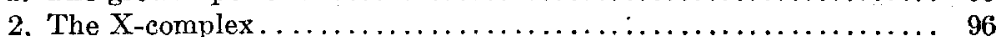

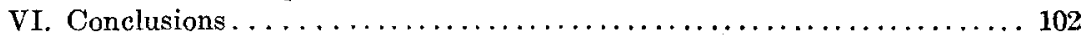

\section{INTRODUCTION}

The formation of the male germ cells of Blaps lusitanica, a large beetle belonging to the family Tenebrionidae, has engaged my attention for more than three years, in an attempt to trace the history of the chromosomes throughout the spermatogenesis. In a first paper ('14) I described in detail the spermatogenesis and the behavior of a peculiar complex - the X-complex, made up of three large chromosomes - throughout the postsynaptic stages and first maturation mitosis. Further progress was made later ('15) and the results obtained in this form confirmed in Blaps waltli Seidl., a closely related species which possesses a similar 
complex. In both papers, however, conflicting results were reached with reference to the number of chromosomes and the composition of the $\mathrm{X}$-complex in $\mathrm{B}$. lusitanica, which seemed to be variable even in the same individual. It was soon realized that these conflicting results were due to imperfect observation rather than to differences in the process of reduction and that further study was needed in order to solve the question.

The present paper is the result of a new investigation of the whole subject, including the reduction of the chromosomes and especially the origin and behavior of the $\mathrm{X}$-complex. The re-

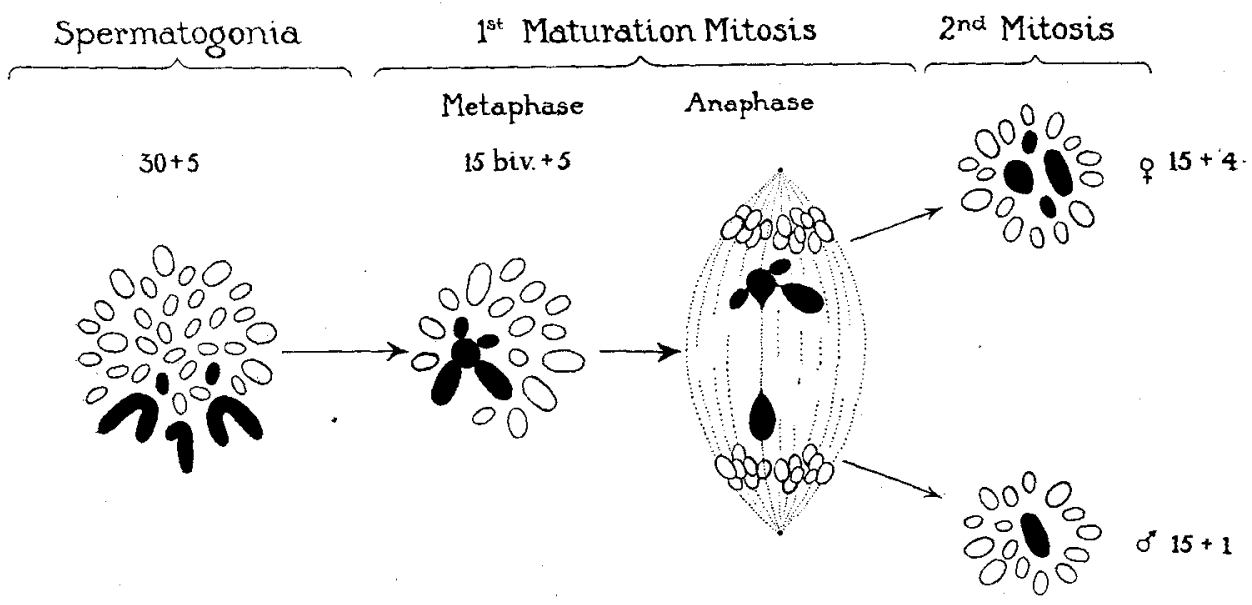

Diagram 1

sults described in the following pages agree, in the main, with those recorded in my previous papers, so far as the features of reduction are concerned, but the conflicting results on the composition of the complex have been cleared up and the conditions upon which the doubts were based carefully compared. I have been fortunate in obtaining a series in which the true composition of the complex could no longer be doubted, since its components are most clearly shown.

Briefly stated, in the spermatogonial mitoses of B. lusitanica thirty-five chromosomes occur, three of which are remarkably large (diagram 1). During synapsis the three large chromosomes and two of the smaller (represented in black in the diagram) 
unite to form the $\mathrm{X}$-complex, while the other chromosomes pair to form fifteen bivalents. In the first maturation mitosis the complex undergoes dissociation, four chromosomes-two large and the two small-passing to one cell, while the third large chromosome enters the other. The final result is the production of two kinds of spermatozoa, one with nineteen chromosomes, the other with only sixteen.

A remarkable feature of the meiotic phase in Blaps is that the complex can be recognized in the spermatocytes at every stage, from the early synapsis to the metaphase of the first maturation division, owing to the fact that one of the large chromosomes appears condensed, like the so-called accessory or X-chromosome of other animals, while the other two large chromosomes persist in the form of long threads united with it. Furthermore, it has been possible to find that the latter do not pair at synapsis, but remain as separate individuals, a fact which led me ('14) to the conclusion that telosynapsis takes place in this case, although the actual pairing of the other chromosomes was never observed.

There are still several points which are left unsolved, since the material in my possession is not especially fit for their solution, but a comparative study of the conditions in other species of Blaps and the preparation of new material of $B$. lusitanica might give the clue to the phenomena described in the following pages.

It gives me great pleasure to express my deep indebtedness to Prof. Edmund B. Wilson, to whom I owe sympathetic interest and valuable criticism throughout my work; also to Prof. Frank R. Lillie, Director of the Marine Biological Laboratory of Woods Hole, for the kind hospitality extended to me in that institution during the summer of 1918. Finally, and not the least, to the Junta para Ampliación de Estudios e Investigaciones Cientificas of Madrid, for the fellowship granted, through which it has been possible to continue my studies in this country. 


\section{MATERIAL AND METHODS}

Blaps lusitanica Herbst is common in woods and uncultivated places near Madrid, Spain, and is usually found in the holes inhabited by rabbits, which it does not leave except at sunset and during the night. All the individuals studied were collected almost in the same spot, in a place known as Puerta de Hierro, during three consecutive years. The specimens were killed by means of chloroform vapor shortly after their capture. Several preserving fluids have been used with variable results; Bouin's fluid, Lenhossek's alcoholic sublimate, and Carazzi's modification of Gilson's fluid proved to be the best, and the most valuable slides were thus obtained. Zenker's fluid and Vom Rath's picro-acetic sublimate gave rather good results, but the mitochondria appear stained to some extent when using iron hematoxylin, and this hampers the accurate study of the chromosomes in the maturation divisions; for this reason these fluids were not used extensively. Flemming's strong and weak solutions have been a complete failure in my hands, the testes being so large that the reagent penetrates with difficulty, while the thick adipose tissue enveloping the organ reduces the osmic acid and prevents its access to the interior of the follicles; hence only the periphery of these is suited for study.

The testes embedded in paraffin were cut into sections from 6 to $10 \mu$ thick. A few stains have been used, most of the slides being stained with iron hematoxylin, orange $\mathrm{G}$ and light green as counterstains. The results obtained with safranin and light green, after preservation with sublimate mixtures or Bouin's fluid, proved to be very meager.

I have never succeeded in making smears and hence have been deprived in my study of the valuable results thus to be obtained.

\section{THE SPERMATOGONIAL MITOSES}

Seriation of the stages. A very important and often difficult point in the study of spermatogenesis is the seriation of the stages. In Blaps the seriation is very easy on account of the way in which the cysts are produced. Although the latter arise 
in the terminal cap, which is a zone occupying the distal end of each follicle, very often only those produced in its central area are apt to go through all the stages of spermatogenesis; while those lying in the periphery usually degenerate. Thus a stream of cysts, as it were, containing all the stages, is produced. Furthermore, the cells of a cyst usually do not appear in the same stage; this is specially. true in the case of those dividing. One can find, for instance, even in the same section, all the stages connecting the metaphase with the late anaphase. This happens not only in the spermatogonia, but also in the spermatocytes, and owing to this fact more than one point which otherwise would appear puzzling has been settled beyond any doubt.

The spermatogonial mitoses. Since in my first paper ('14) I dealt extensively with the spermatogonial mitoses, it seems unnecessary to give a detailed account of them now. The main stages have been represented in figures 8 to 35 , which speak for themselves. Only a few details are considered here, most of them outlined in my previous work.

During the resting stage of the early generations of spermatogonia, the chromatin is scattered throughout the nuclear cavity, forming irregular masses made up of granules, located near or at the periphery, in contact with the nuclear membrane. A large chromosome occurs in these cells, which retains more or less clearly its individuality throughout the resting condition; its appearance varies greatly according to the size of the chromatin masses of which it is made up, which may be very small and regular, placed along a thread (figs. 1, 2, and $7, a$ ), or coarse and unequal (figs. 3 to 5 and $7, b, c$ ). In some cases it appears as a condensed, more or less V-shaped chromosome of ragged outline (fig. 6). Whether or not this body represents the X-chromosome which later appears condensed in the spermatocyte is a question rather difficult to answer. However, the fact that it retains its individuality and that in the early spermatocytes a similar chromosome is found, which could be traced to the condensed body of the later stages, makes this assumption highly probable. 
In all the individuals studied the spermatogonial metaphases contained normally thirty-five chromosomes (figs. 16 to 20). Three of them are readily identified on account of their large size and peculiar shape, as they almost always appear as curved, V-shaped rods, rarely straight or slightly bent, the arms of the $\mathrm{V}$ being of unequal length. Although their position in the metaphase is variable it is commonly peripheral.

It has been possible to find a correspondence in shape and size between two of the large chromosomes (figs. 16 to $20, M, M^{\prime}$ ), while the third chromosome differs from them in both shape and size. The latter was identified in my former papers as the accessory or X-chromosome. The paired large chromosomes were first termed 'chromosomes $a$ and $b$ ' ('14, p. 36) and subsequently 'macrochromosomes' or more simply, 'M-chromosomes' ('15, p. 150 ), which name I will use in the present paper.

In spite of some variation in shape and size in the large chromosomes, found even in the same individual (fig. 21), the differences mentioned above are almost always present. Furthermore, their mode of attachment to the spindle fibers, better seen in the early anaphase (figs. 23 to 27 ), strengthens this view. While the attachment is telomitic (Carothers, '17) for all the small chromosomes (fig. 27), it is clearly atelomitic for the large ones, but a difference is perceptible in the latter: the M-chromosomes possess a submedian attachment, while that of the X-chromosome is subterminal or nearly so. These conditions are already detected in the equatorial plate, as shown by the bending of the rod, except when the chromosomes appear as straight or slightly curved rods (fig. $21 a, c, d, e$ ), in which case it is very difficult to ascertain the point of attachment of the fiber. No telomitic attachment in these chromosomes was ever found; it seems quite possible that the bending may appear when the spindle fibers being to pull the two halves apart.

The small chromosomes appear as oval or elliptical bodies which have no constant position in the metaphase. In normal cells their number is thirty-two, but occasionally one or two more, or fewer may appear. In the first case this is probably due to their fragmentation; in the second to clumping. On the 
whole, their number is fairly constant in every individual studied. I have failed in several attempts to arrange the small chromosomes in pairs. In a few cases this could be done, but their small size prevents aceurate measurements and comparisons. It is obvious that at least two or three pairs can be recognized, but it is very difficult to find such a pairing in the others.

The two small chromosomes which enter the complex are not distinguishable from the others either in shape or size. Since the other thirty pair during synapsis, giving rise to fifteen bivalents, it seems advisable to speak of them as the euchromosomes (McClung, '14) in the description of the spermatocytes.

During the resting condition of the spermatogonia the centrosome is placed somewhere between the nucleus and the mitosome or spindle remnant; this is specially seen when the cells assume a conical shape, the mitosome in this case being placed at the pointed end. Later on, during the prophase, the centrosome comes in contact with the nuclear membrane- if it was not before-and the astral rays are conspicuous at this time (fig. 13).

The centrosome takes this position during the telophase or even at the beginning of this stage (fig. 31), moving along one of the sides of the nucleus. Figures 32 to 34 show some stages of this migration. In figure 32, upper cell, the centrosome, which since the late anaphase has two minute centrioles, still keeps its position in one of the poles of the already vanished spindle, but this position is unusual. In the lower cell of the same figure it is seen at the left of the nucleus. In figure 33 it is clearly detected in the lower cell, while in figure 34 it appears in both daughter cells. When the remnants of the spindle contract and condense to form the mitosome, the centrosome takes its final position (fig. 35) and upon elongation of the cell body usually loses all contact with the nuclear membrane.

As a further proof supporting this account, it must be stated that in some spermatogonia in which the oval shape of the telophasic nucleus is retained, the free ends of the large chromosomes, as seen in the prophase, are directed toward the centrosome (fig. 12); had not the latter moved around the nucleus, the conditions would be the reverse, with the apices of the loops nearer 
the centrosome. This might be accomplished by a rotation of the nuclear contents, as described in the early spermatocytes of Batracoseps by Janssens ('03, '05). Such, however, is not the case in Blaps; since the mitosome does not move from its place of origin and often may be recognized more or less clearly during several cell generations, it offers a fixed point of reference. If a rotation of the nuclear contents took place, the centrosome would always appear in the half of the cell opposite to that containing the mitosome. Furthermore, no telokinetic movements of the nucleus were observed, as the figures show; even if the nucleus turned around the centrosome (the latter retaining its primitive position), the apices of the loops would still be directed toward the centrosome.

\section{THE SPERMATOCYTES}

\section{The maturation mitoses}

The first maturation mitosis is reductional for the $\mathrm{X}$-complex. In the course of the two maturation divisions the bivalent euchromosomes, as usual, divide along two planes cutting each other at an angle of $90^{\circ}$ and their transverse fission takes place in the first mitosis. It seems likely that the latter segregates two homologous chromosomes, paired during synapsis and placed end to end in the metaphase, but we lack conclusive proof of this conclusion. The absence of conspicuous tetrads makes very uncertain the recognition of the spacial relation of the chromatids in each pair, and this is more important than the direction of the plane along which division takes place. The fact that the $\mathrm{X}$-complex undergoes dissociation during the first mitosis does not prove the reductional character of this division for the euchromosomes, since several cases have been described in which the behavior of the sex chromosomes differs in this respect.

A. First maturation mitosis. Prophase. At the end of the prophase, when the condensation of the chromosomes makes possible their certain recognition as separate individuals, these bodies may be grouped in two sets, one represented by the large $\mathrm{X}$-complex (fig. $36, b$ ), the other by fifteen bivalent euchromo- 
somes, the total number being sixteen, counting the multiple complex as one (fig. 37).

The appearance of the chromosomes in the early prophase is somewhat different. Unfortunately, it was not possible to trace in detail all the changes the euchromosomes undergo and the manner in which they are brought about, because of their small size and to some extent also because of the methods of preservation used. The evidence on this point is so meager that I will offer only a short description of this interesting process, without any attempt to draw conclusions of general bearing.

At the end of the growth period there is a diplotene stage during which the euchromosomes appear longitudinally double, each half probably representing an univalent chromosome. The diplotene stage is of a short duration, passing directly into the condensed chromosomes found in later stages without an intervening confused stage such as occurs in other beetles. In some of the euchromosomes the splitting is not complete, both halves being connected with each other at one of their ends, and in this way V's or Y's are formed (figs. 39 and $40, \alpha, e$ ). The splitting may also begin at both ends of the chromosome, the halves thus produced being united at the center (fig. $40, f$ ) often by several anastomoses. When they diverge at the ends X's arise, although it is quite possible that in this case both halves are crossed over each other (fig. $40, g$ ).

These facts point to the existence of different methods leading to the formation of the condensed bivalents and, probably, these methods are related to individual chromosomes, but no conclusive evidence on this point has been obtained so far.

No longitudinal cleft was detected in the halves of the bivalents at any stage of condensation. I do not know whether this is a special feature of this species or the result of preservation. No conspicuous tetrads occur, therefore, and the rings and crosses so characteristic of other insects were never observed.

Once these conditions are reached, a condensation of the euchromosomes takes place to form the oval or slightly dumb-bellshaped bodies found at the end of the prophase (figs. 36 and 37 ). Different steps leading to these conditions appear within the 
same nucleus, as shown in figure 38 , in which all the chromosomes of a cell were drawn in their actual position, while in figure 39 they were arranged in a series. Euchromosomes 1 to 3 show a more or less conspicuous splitting, while in the one marked 4 the two halves diverge to produce a V. Euchromosomes 5 and 6 appear as $\mathrm{Y}$-shaped bodies, seen endwise in 7, 8, and 9. The other chromosomes are well on the way to condensation, which seems to be combined with a displacement of the halves of each bivalent in such a way that both components, which at first were placed side by side, come to lie end to end.

The X-complex appears at the end of the prophase as an approximately $V$-shaped body (figs. $36, b$, and 37 ). Its apex is occupied by a round or oval chromosome which owing to its dense condition retains the stain longer than any of the other

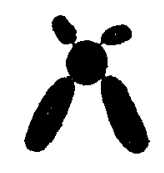

a

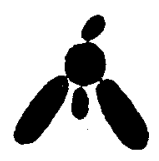

b

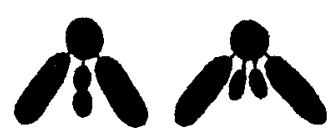

d

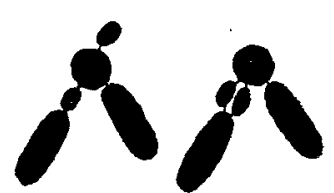

e f

Diagram 2

chromosomes, even in much decolorized slides. This body, as shown by its history throughout the growth period, is the accessory or X-chromosome.

The arms of the V-shaped complex are formed by the Mchromosomes which are less dense. In some complexes the $\mathrm{X}$ chromosome is located in the free end of one of the latter instead of being at the apex of the V, a condition found also in the metaphase.

The small chromosomes of the complex are united with the $\mathrm{X}$-chromosome, but their position is highly variable as shown in figure 41 and diagram 2 . In a few cases one may be united with one of the M-chromosomes, as seen in the same figure $d$, which shows one condensed and lying over the X-chromosome, while the other is still a thin thread connected with one of the Mchromosomes. In most cells, however, the first condition pre- 
vails. At the end of the prophase they are as condensed as the euchromosomes.

In many complexes only one small chromosome is seen (figs. 38, 39 , and $41, e)$, if they are seen at all, the number of euchromosomes in the cell being the normal. Their presence in the complex is, however, evident since the number of the euchromosomes is not increased, a fact still clearer in the metaphase. But an even more conclusive proof is their appearance in the early anaphase, which shows that, at least in some cases, they are placed between the $\mathrm{X}$ and one of the M-chromosomes, which fact may also account for the unequal length of the arms of the V-shaped complex, very conspicuous in some cases.

In sharp contrast with the conditions described in the euchromosomes, the components of the X-complex never appear split lengthwise, either during the short diplotene stage or in subsequent stages of the prophase. In figure 30 of my first paper ('14) I have represented one of the M-chromosomes as split, but this must have been an abnormal condition since I have not been able to find a similar cleft in other cases.

The only change undergone by the complex consists of a condensation of its components (with the exception of the already condensed $\mathrm{X}$-chromosome); this process takes place in several regions (chromomeres) along the chromosomes; hence their segmented appearance. Very often the V-shape of the complex is not assumed until the late prophase, the M-chromosomes appearing in early stages united by their free ends, almost parallel in some instances, curved as to form a ring in others, and in not a few cases crossed over each other (fig. 41, a,e).

Metaphase. Figures 42 to 47 show polar views of metaphases drawn from different individuals, with the exception of figure 46 , which shows four optical sections of a metaphase seen in lateral view. Inspection of such figures shows the irregular position of the euchromosomes with regard to the $\mathrm{X}$-complex, which may occupy the center of the plate or may be located at the periphery; very often it is placed at a different level. Although its presence in normal spermatocytes is absolutely invariable, its shape is highly inconstant. In favorable cases all five components can 
be detected (figs. 42 to 44,46 to $48, a, b$ ), but in many metaphases only one of the small chromosomes is seen (figs. 45 and $48, c)$, and in others both seem to be absent.

An unusual form of complex is represented in figures 47 and $48, b$, in which the $\mathrm{X}$-chromosome failed to condense at the beginning of the growth period and appears as a curved, more or less V-shaped body, united at the ends with the M-chromosomes. The small chromosomes are easily recognized here, lying at slightly different levels and connected with the X-chromosome by means of delicate threads.

Although the preserving fluids used are not the best to show clearly the spindle fibers, it was possible to detect their mode of attachment to the complex. The normal attachment is seen in figure $46, b$. One spindle fiber is attached to the $\mathrm{X}$-chromosome, another to one of the M-chromosomes; the other Mchromosome and the small chromosomes lack a spindle fiber of their own. There are, however, some variations in this respect, which will be described later. The euchromosomes possess a double attachment, both fibers being attached at their ends so that their longer axis is parallel to the axis of the mitotic figure.

Anaphase. The most interesting feature of the first maturation mitosis is the distribution of the chromosomes involved in the X-complex among the secondary spermatocytes. As shown in diagram 1, one of the latter receives four of such chromosomes, while the other receives only one. Furthermore, on account of the almost constant position of the X-chromosome in the complex, it was possible to detect its entrance into the spermatocyte receiving four chromosomes. In this way two kinds of secondary spermatocytes arise, one in which the total number of chromosomes is nineteen-15 euchromosomes plus $4 \mathrm{X}$-complex components-the other with sixteen chromosomes-15 euchromosomes plus $1 \mathrm{X}$-complex component.

This distribution is constant in normal cells, but in a few cases the large chromosomes enter the same spermatocyte; there is, however, every reason to believe that the latter does not produce a functional spermatozoon. The irregularities in the distribution of the small chromosomes are of a somewhat wider oceur- 
rence, judging from the slight numerical variation found in the secondary spermatocytes.

The dissociation of the complex usually takes place when the already divided euchromosomes are on their way to the poles of the spindle. It starts with the loosening of the links which hold the chromosomes together, followed by their partial separation; for, in the early anaphase at least, they remain bound together by means of connecting fibers (figs. 49 to 51). The $X-$ chromosome and that M-chromosome which possesses a fiber attachment separate and pass to opposite poles of the spindle, while the remaining $\mathrm{M}$-chromosome (which lacks a spindle fiber) accompanies the $\mathrm{X}$-chromosome (figs. 49 to 52). In the late anaphase, when the euchromosomes become crowded at the poles of the spindle, it is still possible to detect the large chromosomes outside of the clumped smaller ones and thus to be sure of their final distribution.

The two small chromosomes of the complex are easily detected when only fused with the $\mathrm{X}$-chromosome, as they appear as more or less conspicuous knobs on the surface of the latter (figs. 49 and 50 ); in other cases, however, their recognition is not possible until the components of the complex have entirely separated. I was at first inclined to admit their absence in such complexes, but, fortunately, the presence of a closely graded series of stages in a single cyst enabled me to trace their history during the anaphase, which has been confirmed by the inspection of many other cells in mitosis.

The study of the complexes undergoing dissociation shows that the small chromosomes may be situated between the X-chromosome and the M-chromosomes, and hence they escape detection in earlier stages. When lying between the $\mathrm{X}$-chromosome and the antagonistic M-chromosome (which passes to the opposite pole of the spindle) at the beginning of dissociation, a connecting bridge appears between the X-chromosome and the M-chromosome (fig. 54, a); in some cases this bridge is split lengthwise $(b)$. As the separation of the large chromosomes progresses the small ones gradually emerge from this connecting tract and finally become conspicuous, lying either end to end $(e)$ or side by side 
$(c, d)$. The split condition of the bridge seems to be connected with the last position.

It is obvious that in the normal anaphases both small chromosomes go into the same cell as the $\mathrm{X}$-chromosome, as proved by the number of chromosomes present in polar (fig. 53) and lateral views (figs. 49 and 50) of the late anaphase. In the latter they are well separated from the large chromosomes but always located in their immediate vicinity, the whole group lagging behind the euchromosomes (figs. 51 and 52). On the other hand, conditions similar to that represented in figure $54, f$, point to irregularities in their distribution; the small chromosomes of this complex appear to pass to the cell which does not receive the accessory. It is questionable whether both enter the same cell or whether they separate a little later, but in any case the close connection of one of them with the M-chromosome leads to this conclusion. This unusual distribution might be explained as a result of the passive rôle of the small chromosomes and their connections with the other components of the complex.

One of the causes of the abnormal distribution of the chromosomes of the complex is found in the fact that the spindle fibers may have an attachment different from that described in the metaphase. In a few instances neither M-chromosome is attached to a spindle fiber of its own; in this case the attachment is normal for the X-chromosome, but one of the small components has taken the place of the former. The result in this case may be inferred upon inspection of figure $55, b, c$. The small chromosome, which here takes the place of one of the large ones, probably does not separate from the others, but enters the same cell with them, although it is considerably stretched. The normal distribution of the chromosomes is, however, not brought about, for both M-chromosomes now behave as passive bodies and are drawn into the same cell. This may account for the existence of secondary spermatocytes containing all the components of the complex together with the haploid number of euchromosomes, a condition which at first appeared very difficult to explain, for had the separation of the daughter cells failed to take place, the diploid number of euchromosomes would have been retained. 
In other cases the distribution of the euchromosomes is quite irregular, the number of chromosomes in the secondary spermatocytes showing a surprising variation. I wish merely to emphasize this fact without attempting to give its explanation, since positive facts concerning the irregularities of distribution are lacking at present.

$B$. The secondary spermatocytes and the second maturation mitosis. At the end of the anaphase of the first mitosis the chromosomes become crowded in the poles of the spindle. When the daughter cells separate they become looser and are disposed near the periphery of a vacuole-like nucleus, without losing their dense appearance, although they become a little ragged in outline. By this time the spindle of the second division has appeared and 'soon all the chromosomes enter in the metaphase.

In the latter two large chromosomes of the $\mathrm{X}$-complex, slightly elongated and quite separated from each other, can be recognized in about half of the cells, while the other half has only one such chromosome (figs. 56 and 58). The small chromosomes are no longer distinguishable from the euchromosomes.

The numerical variation already referred to is very conspicuous at this time. Figure 59 shows a metaphase of a spermatocyte lacking the $\mathrm{X}$-chromosome in which seventeen chromosomes occur. This number may be explained on the assumption that both small chromosomes passed to the cell without the X-chromosome, as suggested by figure $54, f$.

Corresponding variations occur in spermatocytes with the $\mathrm{X}$ chromosome, where the normal number may be decreased by one or two (fig. 57). There is always the possibility in this case that one or both small chromosomes may be still fused with the $\mathrm{X}$-chromosome and do not appear as separate individuals, but the increase in the number of chromosomes in the spermatocytes of the other kind clearly shows that irregularities certainly occur.

The division of the chromosomes takes place in the same way as in the spermatogonial mitoses, namely, the chromosomes split lengthwise and the halves thus produced are distributed among the spermatids (figs. 60 to 63 ). The latter no longer show condensed chromosomes and all appear alike despite the differences 
of the chromatin contents due to the unequal distribution of the chromosomes of the $\mathrm{X}$-complex during the reductional mitosis.

\section{The growth period}

The absence of a confused or reticular stage in the growing spermatocytes makes possible the recognition of independent chromosomes throughout the greater part of the growth period. No attempt has been made to trace in detail the history of the euchromosomes, but their condition in the different stages is described for comparison with that of the chromosomes of the $\mathrm{X}$-complex. The behavior of the latter is extremely interesting and stands in sharp contrast with that of the euchromosomes, since they are brought together slightly before synapsis, but remain independent to some extent forming a loose complex, without being actually paired and, therefore, show their univalent nature throughout the postsynaptic stages.

The presynaptic stages can be classified as follows:

$a$. The resting stage, which is but an extended telophase of the last spermatogonial mitosis, the nuclei closely resembling in structure those of the spermatogonia.

$b$. The prochromosome stage, during which the chromosomes appear as massive bodies located near the periphery of the nucleus.

c. The synizesis stage, in which the prochromosomes move to that pole of the nucleus which is nearest the sphere and centrosome, as in the ordinary contraction figure.

$d$. The unraveling stage, representing the transition between the prochromosomes and the leptotene threads, the chromosomes appearing as convoluted threads.

$e$. The leptotene stage, in which thin threads occur.

Stages $a$ and $c$ are highly characteristic of Blaps. The prochromosomes have been described several times in animals, but in no case, I believe, has synizesis been described when the chromosomes are in such a condition.

Synapsis probably takes place when the leptotene stage is reached, but on account of the crowded condition of the chromo- 
somes, which still occupy one of the halves of the nucleus, it is very difficult to observe their actual pairing. Moreover, since the X-complex arises before the leptotene threads are formed, it is possible that synapsis takes place also in the prochromosome stage. Therefore, it seemed inadvisable to recognize a definite synaptic stage.

The postsynaptic stages are the following:

$f$. The early pachytene stage, in which the bivalent euchromosomes are confined to one of the nuclear hemispheres and produce a condition which could be compared to the bouquet stage in other animals.

g. The pachytene stage proper, with thick and apparently undivided threads scattered within the nucleus.

$h$. The diplotene stage, during which the euchromosomes split lengthwise; this stage leads gradually to the prophase of the first maturation division.

Since the behavior of the chromosomes of the X-complex differs from that of the euchromosomes, it has seemed advisable, for the sake of clearness, to consider it separately.

A. Presynaptic stages and synapsis. a. Resting stage. There is no doubt that a resting stage intervenes between the last spermatogonial anaphase and the prochromosome stage, for, besides the evidence furnished by the seriation of the stages, spermatocytes in both conditions were found within the same cyst (fig. 64).

With exception of the spermatids, the resting spermatocytes are the smallest cells in the testis. The chromatin appears in their nuclei as scattered masses very similar to those described in the spermatogonia (fig. 65); as in the latter, a deeply stained mass of chromatin can be detected sometimes, resembling more or less closely a chromosome with very ragged outline, often broken up into several masses. This body is the $\mathrm{X}$-chromosome and its history could be traced to the succeeding stages.

The condition of the chromosomes is brought about by the same process as in the spermatogonial anaphases. In no case do the chromosomes retain their dense condition, but they pass into the stage just described, which appears to be of rather long 
duration, if we may judge from the considerable number of cysts showing such cells.

b. Prochromosome stage. In this stage (figs. 67 to 70 ) the chromatin appears in the form of condensed bodies located at the periphery of the nucleus in close contact with the nuclear membrane; hence in optical section the center of the nucleus is deprived of chromatin (fig. 67, cell to the right). The number of massive bodies, which I formerly called 'cromosomas preleptoténicos' (since from each of them a leptotene thread arises), agrees with the diploid number, as already stated in my second paper ('15, p. 157). Reexamination has proved the correctness of this assumption. In some cells it is very difficult to be sure of their exact number, but even so we can be almost certain that it seldom exceeds or falls short of the diploid number. Thus, in the cells represented in figure 70 , in which the prochromosomes were drawn from the same cell, thirty-six dense bodies occur. This slight increase may be due either to one of the less dense masses being nothing but residual chromatin or to one chromosome being cut into two, as drawings $c$ and $d$ are from different sections. The large chromosomes of the complex can be distinguished in most of the cells, a description of them being given later.

The process by which the prochromosomes arise is worthy of mention. The scattered chromatin granules gather in certain places (fig. 66) and, upon further condensation, form the prochromosomes. Although these resemble very much the chromosomes of the metaphase in the spermatogonial mitoses, no threads take part in their formation; hence we cannot speak of a true prophase, since the difference between the two processes is obvious. I would suggest that this process might well be called a 'pseudoprophase,' since the dense chromosomes arise from chromatin masses without passing through the normal stages of spireme chromosomes. An early stage of this process is represented in figure 66 . The cell to the left in figure 67 , which represents a polar view of a spermatocyte, shows prochromosomes of irregular outline which precede the denser bodies. The condensation, however, never goes so far as to produce the chromosomes with smooth outlines characteristic of mitosis. 
c. Synizesis. So far as the euchromosomes are concerned, very little can be added to my former account of this stage ('14, p. 55). Once formed, these bodies begin to shift their peripheral position and become crowded near that pole of the nucleus nearest the sphere and centrosome. The degree of contraction is slightly variable according to the individual; in some specimens a mass of clumped chromosomes is formed, in which it is impossible to detect individual chromosomes, while in others the process does not go so far, although the chromosomes become restricted to a half of the nucleus.

This stage represents the synizesis of other forms, with only the difference that, whereas in the latter the contraction usually takes place after the leptotene threads have arisen, in Blaps it occurs at an earlier stage. Figure 71 shows the beginning of the process. In figure 72 two cells in this stage have been represented; the nucleus in the cell to the left is seen in optical section. Figure 73 shows the same condition as seen in polar view.

d. Unraveling stage. This stage is marked, as in other forms, by a resolution of all the prochromosomes (with the exception of the X-chromosome) into closely convoluted threads which then unravel to form the thin threads of the succeeding stage. This process is rather difficult to follow in the euchromosomes on account of their small size and crowded condition at the pole of the nucleus, but in the M-chromosomes it is almost as conspicuous as in the best objects that have been studied (fig. 76, $a, b$ ).

The polar position of the prochromosomes is retained during the unraveling stage. Figure 75 shows some phases of this process in a spermatocyte seen in polar view; some threads have already appeared, other prochromosomes are unraveling and a few are still in the massive condition.

e. Leptotene stage. The leptotene threads produced by the process just described are restricted to the pole of the nucleus in contact with the sphere. In polar views it is possible to detect the presence of delicate threads, somewhat wavy in appearance, the shortest of which are the euchromosomes and small components of the X-complex (fig. 77). Two other threads, much longer, conspicuous, and connected with a dense mass, are the 
M-chromosomes, which also undergo a process of unraveling. In side views of the nucleus all that can be seen is a mass of closely interwoven threads from which some filaments emerge, spreading in the nuclear cavity (fig. 78, left of the nucleus), but on the whole they remain crowded at the pole nearest to the sphere. A comparison between the euchromosomes and M-chromosomes fails to show any other difference than the greater length of the latter.

Synapsis. Observation of the actual pairing of the euchromosomes to form the pachytene threads is exceedingly difficult in Blaps on account of the contraction of the chromatin and, in spite of several attempts to solve this question, no positive results could be obtained. It is true that here and there it is possible to find parallel leptotene threads which might be regarded as the early zygotene condition, but the $Y$ figures, so conspicuous in the nuclei of the spermatocytes of other animals, and the progressive formation of thick threads by the close association of a pair of leptotene threads could not be detected in my material.

The question of synapsis is therefore unsettled, so far as the euchromosomes is concerned. Judging from the clefts occasionally seen in the euchromosomes during the early pachytene stage and the longitudinal split seen before the prophase of the first maturation division, some ground is given for the belief that parasynapsis takes place.

B. Postsynaptic stages. f. Early pachytene stage. Nuclei in this stage are found in cysts containing spermatocytes in the leptotene condition. The stage is characterized by the presence of thick rods, straight, slightly curved, or very often V-shaped. In a few of these rods (fig. 80) a longitudinal cleft or space may be detected, which seems to correspond to a place in which the conjugating chromosomes are still separated. In slightly later stages this cleft disappears, the euchromosomes becoming thick and continuous throughout (fig. 79).

As a result of the pairing of the chromosomes, the dense condition of the synaptic knot gives way to a somewhat looser mass which begins to spread slowly throughout the nuclear cavity. There is no definite orientation of the chromosomes at this stage. 
A few V-shaped rods have their free ends directed toward the sphere, but this is inconstant. It is questionable whether their arrangement is merely accidental or constant for some euchromosomes, the former assumption being most probable. Hence it is not possible to speak of a bouquet stage. This term was adopted in my first paper, but the comparison with forms in which this stage appears very marked shows that a great difference exists in this respect.

g. Pachytene stage proper. The chromosomes in this stage appear spread throughout the nucleus without definite orientation and are probably connected with each other by means of very delicate threads. As in the preceding stage, each euchromosome is a thick rod in which, at first, no split can be detected. In the late pachytene nuclei, however, a few chromosomes show the beginning of the longitudinal split of the succeeding stage. The bivalent euchromosomes are continuous throughout; the chromatin granules do not show an arrangement into two series, which would suggest the existence of two conjugated chromosomes.

h. Diplotene stage. As already mentioned, this stage lasts but a short time and immediately precedes the formation of the dense bivalents of the first maturation mitosis. It is questionable, therefore, whether we should consider such a condition as a separate stage. Nothing can be added to the description already given in the preceding pages.

C. The X-complex during the growth period. The X-complex is formed at the beginning of synizesis. Its components, separated up to this time and often scattered throughout the nucleus, come closer together and finally form a group which, from this moment, behaves as a single unit, moving to the pole nearest to the sphere along with the euchromosomes (fig. 71). At least the three large components can be detected and, in favorable cases, one or two smaller masses, which represent the small chromosomes, are also found in close contact with the former. One of the large chromosomes appears somewhat denser than the others and retains this condition in the succeeding stages. This body is the $\mathrm{X}$ - or accessory chromosome. Its earlier history differs 
from that of the M-chromosomes. When the prochromosomes are condensing the $\mathrm{X}$-chromosome appears as a $\mathrm{V}$ - or $\mathrm{J}$-shaped body (fig. 67, cell to the left); once the massive condition of the former is reached, it becomes looser in structure, finally unraveling in a thick, coarse thread of ragged outline (figs. 68, 69, and $70, a)$. A condensation follows and the deeply stained body of later stages is formed. The process of condensation must take place rapidly, since I have not been able to find stages leading to this condition. Even when found it would be very difficult to decide whether condensation or unraveling is taking place.

It may happen that one of the M-chromosomes also unravels at this time, or at least becomes looser in structure (fig. 70, $M$ ); perhaps this is but the result of deferred condensation. The close proximity of this $\mathrm{M}$-chromosome and the $\mathrm{X}$-chromosome in the figure and their connection by means of delicate fibers is suggestive of an influence of the latter on the M-chromosome, but conclusive evidence on this point is lacking, since this appearance is far from common.

The M-chromosomes, and probably also the small chromosomes, behave from this moment like the euchromosomes, so far as the unraveling process is concerned. When the latter begin to unravel, the M-chromosomes become looser in structure, and each gives rise to a tightly convoluted thread which, on account of its considerable length, spreads throughout the nuclear cavity. Two details of the unraveling process are shown in figure 76 ; in figure 78 the leptotene M-chromosomes still exhibit a wavy appearance which is less conspicuous in those of figure 77 . It is very difficult to follow the unraveling of the small chromosomes, since in most of the cases the $\mathrm{X}$-chromosome, to which they are united, lies in the mass of chromosomes located in one of the nuclear poles.

It is an interesting fact that the M-chromosomes preserve their original thickness during the early pachytene condition and appear as separate individuals connected with the $\mathrm{X}$-chromosome by one of their ends. A comparison of figures 77 and 78 (which represent the leptotene stage) with figures 79 and 80 , which are nuclei in the early pachtyene stage, shows this condition very 
clearly. In figure 80 a portion of the M-chromosomes has been cut by the knife, the X-chromosome appearing separated from the former. These relations are preserved in figure 79.

A little later the M-chromosomes become shorter, and correspondingly thicker. Assuming that parasynapsis occurs in these chromosomes, we ought to find some cells in which a single thick thread is connected with the X-chromosome, but careful search failed to reveal such a condition, the relations just described occurring in hundreds of cells. Occasionally the M-chromosomes are not visible, being entangled in the mass of euchromosomes, but wherever they appear one can be sure that they are separated. During the pachytene stage proper the complex stands out quite sharply within the nucleus. It is possible to detect the relations of the M-chromosomes and the accessory in almost every cell, and in many complexes the small chromosomes are united with the accessory. Perhaps the clearest case of this is represented in figure 26 of my first paper, in which this relation was thought to be accidental.

At this time two varieties of complexes are found. In one the $\mathrm{X}$-chromosome is situated between the two M-chromosomes (figs. 82,83 , and 84) which are often united by the opposite ends by a very thin thread. In the other kind, already represented in the paper just mentioned, the X-chromosome is at the extremity of one of the M-chromosomes, which are directly united with each other. I do not believe that the last arrangement is accidental, for similar complexes occur rather often during this stage as well as during the prophase and metaphase of the first maturation division. That the M-chromosomes are united directly by one of their ends is obvious, for the length of the single thread thus formed is approximately twice that of each M-chromosome (figs. 81,85 , and 86 ).

It is interesting to note that the length of the M-chromosomes is sometimes unequal. Thus in figure 84 the thread at the right is shorter, as shown by the break in outline which marks the distal ends of both M-chromosomes, connected here by a thread. No small chromosomes were visible in this case. It is quite possible that such inequality is due to the interpolation of the latter be- 
tween the M-chromosomes and the X-chromosome, a fact which stands out very clearly during the dissociation of some of the complexes. The same could be said of figure 83. Here a small portion of one of the small chromosomes is seen to the left of the $\mathrm{X}$-chromosome. The $\mathrm{M}$-chromosome to the right is shorter than that to the left, and a break of outline suggests that this inequality is also due to the interpolation of the other small chromosome, otherwise apparently lacking. It might be well to emphasize that this peculiarity was discovered some time after the figures were drawn, when the intermediate position of the small chromosomes in the dissociating complex was definitely established.

During the pachytene stage the M-chromosomes are approximately as thick as the euchromosomes. However, the latter are double, as shown by the splitting which appears during the short diplotene condition. I think there can be no doubt about the univalent character of the M-chromosomes, for if we consider them as double, their number in the spermatogonia should be four instead of two, an open contradiction with the facts. Assuming that the M-chromosomes are ordinary chromosomes, as indicated by their structure throughout the growth period, I thought ('14) there was evidence in favor of telosynapsis for the euchromosomes. The splitting of the diplotene stage was regarded as the plane of the equational division, which was already present even before the first division had taken place. I am more inclined at present to admit the existence of parasynapsis, although there is not conclusive evidence supporting this view.

If parasynapsis really occur, we cannot fail to recognize that the behavior of the M-chromosomes in this respect is entirely different from that of the euchromosomes. Furthermore, the direct connection of the $\mathrm{X}$-chromosomes and the interpolation of the small chromosomes between the latter and the X-chromosome removes the possibility of a normal parasynaptic association, or at least makes it very problematical.

The importance of the behavior of the M-chromosomes for the interpretation of the complex will be discussed elsewhere. 


\section{DISCUSSION}

\section{The growth period}

There are two points in the growth period of Blaps which, I believe, deserve special attention, inasmuch as they are highly characteristic of this species. One is the presence of a resting or confused stage connecting the anaphase of the last spermatogonial division with the prochromosome stage. The other is the occurrence of synizesis before the unraveling stage. Both conditions, already described in my earlier papers, have been found in all the individuals studied so far, irrespective of the fluids used in the preservation of the material, and therefore seem to be entirely normal.

The massive prochromosomes have been found in several forms in both animals and plants, and in many cases appear to be derived directly from the anaphase chromosomes, without an intervening confused stage. But in other instances the telophase of the last spermatogonial mitosis may go so far as to produce a coarse network in which it is impossible to detect individual chromosomes. Such a condition has been described by Professor Wilson in Lygaeus and Oncopeltus ('12); in the former, cells with a nuclear network occur together with spermatogonial anaphases within the same cyst. However, it could not be proved whether or not the latter were those of the last spermatogonial division. On the other hand, it was impossible, too, to trace step by step the origin of the massive prochromosomes, "for there is no way of demonstrating the seriation at this time, and the change is probably effected rapidly" ('12, p. 367).

We have in Blaps a clear case in which the prochromosomes arise from a network, as proved by the seriation of the stages, very easily seen in this form, and by the fact that the origin of such bodies could be traced even within the same cyst. The evidence seems to be conclusive, if we keep in mind that both conditions are occasionally found within the same cyst and that the seriation of later stages, on the one hand, and the conspicuous difference in size between the cells in both stages, on the other, do not warrant another interpretation. 
The presence of massive prochromosomes is not of general occurrence among the Coleoptera. While it has been possible to find in Blaps hundreds of cysts in such a condition, it is evident that they are lacking altogether in other species. Miss Stevens ('06, '09), who studied more than forty species of beetles, found them in but two species-Photinus pennsylvanicus and Limoneus griseus. She maintained that they are traceable directly to the chromosomes of the anaphase; indeed, they are but those chromosomes which have retained their massive condition for some time. Arnold ('08) has described similar bodies in the early spermatocyte of Hydrophilus piceus, and states that each of them represents a somatic chromosome, although he gives no definite proof of this assertion. According to the descriptions of this author, there is not a confused stage between the last anaphase and the prochromosomes.

Owing to the presence of such a confused stage in Blaps, we face here a serious difficulty in assuming that the prochromosomes are the representatives of the chromosomes of the spermatogonia. If there have been sharp criticism of this view when they arise directly from such chromosomes, still more skepticism will arise when considering that their individuality is apparently lost in a coarse network. We have, however, strong reasons favoring the former view, since the number of prochromosomes agrees with the diploid number and the large chromosomes can be recognized as separated individuals during this stage. I wish, however, to emphasize a point which stands out clearly in studying the chromosomes of Blaps. This is the remarkable plasticity of the chromatin which leads to surprising changes of shape, if not of volume, in the individual chromosomes. This could hardly be due to the effect of the reagents, since it appears in material preserved by different methods. As a result, it is very difficult to establish constant individual differences among the euchromosomes.

The way in which the prochromosomes arise in Blaps suggests a profound reorganization of the chromatin within the prochromosome, a process which might account for the considerable duration of this stage. It is interesting to note that no threads, such 
as those present in the somatic prophase, precede the prochromosomes and that the process which I have ventured to call 'pseudoprophase' seems to be unique in the history of the germ cells. But it is still more interesting when we compare such massive bodies with others, somewhat similar, which occur in the early prophase of the spermatogonia. In these cells the prophase begins with the appearance of thick bands of chromatin, of ragged outline and segmentated appearance (figs. 8 and 9). Near cells with such structure are others which contain nuclei with thin threads (fig. 10,a). A comparison of the two conditions compels us to admit either that the thick bands represent a stage preceding the thick threads or that there are two processes by which the formation of the prophase chromosomes takes place.

The last assumption is not supported by any evidence. On the contrary, there seems to be some proofs in favor of the first view in the conditions described in the spermatogonial prophases of Triton by Janssens ('01) and in those of Phrynotettix by Pinney ('08) and Wenrich ('16). I have failed to find a conclusive proof of such facts in Blaps, although conditions observed strongly point to it. It is possible that the same phenomena, carried to a greater extent, occur in the prochromosomes, for such bodies begin as a mass of chromatin granules and end as a tightly coiled thread.

Perhaps the extent to which this internal reorganization of the chromosomes is carried may be the cause of the apparently precocious synizesis, which also is highly characteristic of Blaps. In other animals and plants the synaptic knot is formed after the leptotene stage is reached or, at least, when the unraveling of the chromosomes is well advanced. On account of the extreme delicacy of the leptotene threads, considerable doubts have been expressed as to the normal occurrence of such contraction, which has been thought by some authors to be an artifact due to the action of the reagents. It seems unnecessary to discuss this point further, since it has been shown that synizesis also takes place in the living cell. Whatever the origin of synizesis may be, it is probably based on a definite phenomenon, the nature of which we cannot understand at present. It might be well to 
emphasize that it appears in my material irrespective of the preserving fluids used, but that individual differences are conspicuous. Without denying some influence on the part of the reagents-e.g., length of preservation, shrinkage due to the embedding process, etc.- the gradual shifting of the massive prochromosomes toward a particular pole of the nucleus is a fact which, I hope, will not fail to impress the mind of any impartial observer.

\section{The X-complex}

The interpretation of the $\mathrm{X}$-complex is at present an exceedingly difficult question. None of the oogonia in mitosis being available, definite knowledge of the number of chromosomes in this sex is lacking. This information is of the utmost importance, inasmuch as the $\mathrm{X}$-complex of this form appears as an intermediate condition between such complexes as are made up exclusively of sex chromosomes and those arising by the linkage of one of the latter with a pair of euchromosomes. The data furnished by the study of the conditions in the female will doubtless settle this question, since in the first case we should expect to find an exact duplication of the group of chromosomes entering into one of the secondary spermatocytes, whereas, in the second, only the dense chromosome which appears as a massive body during the growth period would be double.

The view that the $\mathrm{X}$-complex of Blaps is formed by the association of the $\mathrm{X}$-chromosome and a pair of euchromosomes was adopted, too hastily perhaps, in my first paper. Further study showed that in several cases a pair of smaller euchromosomes was also linked with the X-chromosome. On account of the considerable number of metaphases showing this linkage, I was led to believe that such association might well be the normal condition; that the failures of linkage, much less frequent, might be regarded as abnormalities of synapsis ('15, p. 182).

Since evidence enough to support this assumption is lacking, no further attempt to maintain this view will be made here. It seems better to emphasize the differences between the complex under consideration and the conditions observed in other forms, 
inasmuch as on these differences hinges our whole interpretation of the facts.

We might adopt the view that the four chromosomes entering one of the secondary spermatocytes constitute a multiple Xchromosome acting like a unit, while the $\mathrm{M}$-chromosome passing to the other spermatocyte is the so called Y-chromosome; but this encounters serious difficulties. Not the least of these is that we have no conclusive proof that the chromosome thus segregated from the complex is constantly one and the same individual. In the event of marked differences between the M-chromosomes, it would be easy to decide on this point, but the observed differences are far from being constant. Without denying the abovesuggested possibility, we must not overlook another one, namely, that the distribution of the M-chromosomes among the spermatocytes may be a matter of chance, as provied for heteromorphci pairs of euchromosomes in some Orthoptera (Carothers, '13, '17; Voinov, '14; Wenrich, '14, '16; Robertson, '15).

This interpretation is strengthened to some extent by the behavior of the components of the $\mathrm{X}$-complex during the growth period. We cannot understand at present why one of the chromosomes is condensed, showing all the typical features of the sex chromosomes of other animals, while the others closely resemble the conditions of the euchromosomes. Wherever it has been possible to trace the history of a double or multiple $\mathrm{X}$ chromosome, it appears-with the possible exception of Ascaris lumbricoides (Edwards, '10) and Ascaris incurva (Goodrich, '16) -as a group of massive bodies throughout the postsynaptic stages, whether or not associated with a Y-chromosome. It is found in this condition in the spiders (Berry, '06; Wallace, '05, '09; Painter, '14) and in the complexes of some HemipteraFitchia, Rocconota, Conorrhinus, Prionidus, Sinea and Acholla (Payne, '09, '10). In other species they fuse into a single mass in which no individual chromosomes can be detected, as occurs in Galgulus (Payne, '08), Syromastes (Gross, '04; Wilson, '11) and Ascaris canis (Walton, '16). Furthermore, the Y-chromosome, when present, appears always as a massive body. The only exception to this rule is, if I remember correctly, the case of the 
hemipteron Enchenopa (Kornhauser, '14). Perhaps not much stress should be laid on this point since, as a whole, the behavior of the complexes during the growth period is not very accurately known.

The facts just mentioned are in remarkable contrast with the conditions in Blaps and point to another interpretation of the $\mathrm{X}$-complex in the latter case. But we cannot fail to recognize that in Blaps the assumption of a linkage of the $\mathrm{X}$-chromosome with two pairs of euchromosomes of unequal size also meets with important objections. The failure of the M-chromosomes, and, probably also, of the small chromosomes, to pair at synapsis, or, at least, to remain paired during the postsynaptic stages, is a noteworthy feature which departs from the conditions described in other forms. If we regard the $M$-chromosomes as euchromosomes, we must accept the fact that they are of a peculiar kind. I must confess that definite proof showing that the M-chromosomes do not undergo synapsis is lacking at present; indecd, the actual pairing of any chromosomes was never observed in my slides, and the assumption that parasynapsis occurs is merely an inference based on the behavior of the bivalents during the diplotene stage. We can be sure, however, that, in the event of a parasynaptic association of the M-chromosomes, this condition lasts but a short time, since their independence is well shown in the early pachytene nuelei.

It is true that this peculiarity in itself does not give a strong ground for either accepting or rejecting the idea that we are dealing with a pair of euchromosomes linked with the sex chromosome. But since no explanation of the nature of the X-complex is given or even suggested in the present paper, the statement has no other value than the recognition of a fact, the nature of which is still unknown. Further, such a condition is of some theoretical interest, since it proves in an unmistakable way the absence of crossing over for the two sets of hereditary factors located in the M-chromosomes, which, if we judge from the considerable size of the latter, must involve an extensive series of characters. 
In the complexes of Hesperotettix and Mermiria (MeClung, '05, '17), which may be considered as the type of their class, the euchromosomes which are linked with the sex chromosome behave in a normal way, namely, they appear in the prophase, forming a tetrad which suggests a parasynaptic association in earlier stages. The same is true in the case of some specimens of Chorthippus curtipennis (Robertson, '16) and also in Gryllotalpa vulgaris (Voinov, '14) judging from the figures given by this author.

In Hesperotettix and Mermiria the linkage of the X-chromosome with one euchromosome can be detected already in the spermatogonia, a condition most likely to be found in Leptynia (De Sinéty, '01), judging from the even number of chromosomes represented in the figure given by this author. The same relations are alsg present in Anopheles (Stevens, '10, under Culex; '11) in which an XY pair of sex chromosomes occurs, and still more conspicuously in Ascaris megalocephala (Edwards, '10; Frolowa, '12), although in the latter the sex chromosome may occasionally be free (Boring, '09), a condition also found in some individuals in both Hesperotettix and Mermiria.

Since three V-shaped chromosomes exist also in Blaps, I have not overlooked the possibility of a similar linkage. Unfortunately, the most impartial and careful study of my slides fails to show any trace of linkage whatsoever; neither breaks in outline nor differences of structure or staining capacity in the limbs of the $\mathrm{V}$-shaped chromosomes can be detected in this species. The assumption of a linkage of a sex chromosome with an euchromosome, instead of explaining satisfactorily the question at issue, would render it still more complicated in view of the odd number of chromosomes involved and the failure of parasynapsis. It seems plain that the continuity of the three large spermatogonial chromosomes with the large massive bodies of the anaphase of the first maturation division is a fact beyond any doubt.

There is still another point which deserves special attention, and is by no means explicable at present. This is the distribution of the small chromosomes among the secondary spermatocytes, which gives rise to cells with eighteen and seventeen 
chromosomes, respectively. As already mentioned, the normal or, perhaps better, the usual condition is that the small chromosomes pass along with the X-chromosome into the same cell. How the former distribution is brought about I do not know. It is an open question whether or not such cells give rise to functional spermatozoa. If they do, slight numerical variations ought to be found in certain individuals. We have ample proofs on the viability of individuals with a number of chromosomes slightly different from the normal in the species, as furnished by the cases in which supernumerary chromosomes occur, and also by the remarkable case of non-disjunction of the sex chromosomes in Drosophila (Bridges, '16). But, in all the individuals of Blaps so far studied, the number of chromosomes appears to be constant.

Some of the figures on the dissociation of the complex might convey the impression that occasionally the X-chromosome takes the place of one of the M-chromosomes and enters one of the secondary spermatocytes alone. Without denying this possibility, on account of the striking numerical variations observed here and there, I must emphasize the variable position of the $\mathrm{X}$-chromosome with reference to the M-chromosomes. It is evident that in some cases this chromosome is not at the apex, but in the free end of one of the arms of the V-shaped complex. Therefore the M-chromosome, which appears occupying the apex passes alone into one of the spermatoctyes, while the others enter the opposite cell. Under identical conditions the normal distribution may also take place, the $\mathrm{X}$-chromosome, and the $\mathrm{M}$ chromosome to which it is linked, entering the same cell. These facts strongly suggest the possibility of a variation in the fiber attachment, leading to conditions very different from those described in the metaphase and pointing to an efficient distribution of the components of the complex. In teleological language, the most important thing here would be, not the relative position of these components, but their final distribution, and in order to fulfill this end a corresponding variation in the attachment of the spindle fibers takes place. 
It is quite possible that the complex under discussion is present only in some individuals and that the primitive condition would not show such association, the $\mathrm{X}$-chromosome being free as in the vast majority of the beetles hitherto studied. With regard to this point, it seems necessary to emphasize the fact that all my specimens have been collected almost in the same spot and that their number is not considerable, as such conditions ought always to be taken into account in critical cytological research. I do not know, therefore, whether the inspection of individuals from other localities would lead to the same conclusions. It is interesting to note that in Blaps waltli, a closely related but sharply distinct species, a similar complex occurs and that the behavior of this complex during the growth period and first maturation mitosis is the same, although the number and size relations of the chromosomes involved is slightly different. Since I have slides from only three individuals of this species and the technique is not specially favorable for a detailed study, its description has not been included here.

The differences between the X-complex of Blaps and those hitherto known, suggest that we are probably dealing with a condition of the utmost importance in the history of the germ cells, closely related with the evolution of the sex chromatin. The behavior of the chromosomes of the complex gives the impression either that a group of euchromosomes is in the course of secondary association with the sex chromosome or that a large composite X-chromosome is breaking up into several bodies which have not yet attained to complete independence. Which of the two processes is taking place we cannot say at present.

This case is comparable to the interesting XY complex of Notonecta indica, described by Miss Browne ('16), in which the Xchromosome is composite, appearing at the prophase of the first maturation division as a central dense mass and two lateral threads in which an unequal number of knobs occur. Such a condition is regarded by the author as a step in the liberation of chromatin from the sex chromosome. A further step would be represented by Blaps in which the chromosomes have already freed themselves, but still lack the characteristics of the euchro- 
mosomes, so far as synapsis is concerned. But such a conclusion would be of very hypothetical character and is without adequate support in the facts observed elsewhere.

\section{CONCLUSIONS}

1. The spermatogonial groups of Blaps lusitanica contain thirty-five chromosomes, thirty of which pair at synapsis, giving rise to fifteen bivalents in the primary spermatocytes. The other five chromosomes join in a group, the $\mathrm{X}$-complex, during the early synizesis and can be traced from this stage to the metaphase of the first maturation division.

2. The chromosomes of the $\mathrm{X}$-complex differ in size and shape, three of them being much larger than two others which cannot be distinguished from the ordinary chromosomes in the spermatogonia. The large chromosomes appear in the latter as atelomitic V-shaped bodies. Two of them, which appear to be homologous and have been termed M-chromosomes, have a submedian attachment of the spindle fibers, while the third has a subterminal attachment. The latter element, as shown by its behavior during the growth period, corresponds to the accessory or X-chromosome of other forms.

3. A resting stage intervenes between the last spermatogonial mitosis and the prochromosome stage. The prochromosomes appear as massive bodies, their number agreeing with that of the spermatogonial groups.

4. Synizesis takes place when the chromatin is still in the form of massive prochromosomes.

5. During the unraveling stage the M-chromosomes and small chromosomes of the $\mathrm{X}$-complex give rise to leptotene threads, whereas the $\mathrm{X}$-chromosome retains its dense condition.

6 . The M-chromosomes, and probably also the small chromosomes of the $\mathrm{X}$-complex, do not pair at synapsis, but persist throughout the pachytene stage as independent threads connected with the X-chromosome. Their relative position in the complex is variable.

7. The $X$-complex undergoes dissociation during the anaphase of the first maturation mitosis. One of the M-chromosomes 
segregates from the others and passes into one of the secondary spermatocytes, which receives sixteen chromosomes (15 euchromosomes plus 1 chromosome of the $\mathrm{X}$-complex). The other spermatocyte receives nineteen chromosomes ( 15 euchromosomes plus 4 chromosomes of the $\mathrm{X}$-complex).

8. There is no conclusive evidence of predetermination in the segregation of the M-chromosomes during the reduction division. It is possible that their distribution with reference to the $\mathrm{X}$ chromosome follows the law of chance.

9. The chromosomes of the X-complex are separate in the secondary spermatocytes and the two classes of the latter are found in about equal numbers.

10. The second maturation mitosis is equational.

11. The $\mathrm{X}$-complex seems to represent an intermediate condition between complexes made up exclusively of sex chromosomes and those originated by the linkage of a sex chromosome with a pair of ordinary chromosomes. 


\section{LITERATURE CITED}

ARNoLd, G. 1908 The nueleolus and microchromosomes in the spermatogenesis of Hydrophilus piceus. Arch. f. Zellforsch., Bd. 2.

Berry, E. V. 1906 The 'accessory chromosome' in Epeira. Biol. Bull., vol. 11 , no. 4 .

Boring, A. M. 1909 A small chromosome in Ascaris megalocephala. Arch. f. Zellforsch., Bd. 4.

Bridges, C. B. 1916 Non-disjunction as a proof of the chromosome theory of heredity. Genetics, vol. 1.

Browne, E. N. 1916 A comparative study of the chromosomes in six species of Notonecta. Jour. Morph., vol. 27.

Carothers, E. E. 1913 The Mendelian ratio in relation to certain orthopteran chromosomes. Jour. Morph., vol. 24.

1917 The segregation and recombination of homologous chromosomes as found in two genera of Acrididae (Orthoptera). Ibid., vol. 28.

Edwards, C. L. 1910 Idiochromosomes in Assaris megalocephala and Ascaris lumbricoides. Arch. f. Zellforsch., Bd. 5.

Goodrich, H. B. 1916 The germ cells of Ascaris incurva. Jour. Exp. Zool., vol. 21.

Gross, J. 1904 Die Spermatogenese von Syromastes marginatus. Zool. Jahrb., Bd. 20.

Janssens, F. A. 1901 La spermatogénèse chez les tritons. La Cellule, T. 19. 1905 Spermatogénèse dans les batraciens. III. Evolution des auxocytes males du Batracoseps attenuatus. Ibid., T. 22.

Janssens, F. A., кт Dumez, R. 1903 L'élément nucléinien pendant les cinèses de maturation des spermatocytes chez Batracoseps attenuatus et Plethodon cinereus. La Cellule, T. 20.

Kornhauser, S. 1914 A comparative study of the chromosomes in the spermatogenesis of Enchenopa binotata (Say) and Enchenopa (Campylenchia Stal) curvata Fabr. Arch. f. Zellforsch., Bd. 12.

MCCuUng, C. E. 1905 The chromosome complex of orthopteran spermatocytes. Biol. Bull., vol. 9.

1914 A comparative study of the chromosomes in orthopteran spermatogenesis. Jour. Morph., vol. 25.

1917 The multiple chromosomes of Hesperotettix and Mermiria. Ibid., vol. 29.

Nonidez, J. F. 1914 Los cromosomas en la espermatogénesis del Blaps lusitanica Herbst. Trab. Mus. Ciene. Natur. Madrid, Ser. Zool. num. 18. 1915 Estudios sobre las células sexuales. I. Los cromosomas goniales y las mitosis de maduración en Blaps lusitanica y B. waltli. Mem. Soc. Espan. Hist. Nat., T. 10.

Painter, T. S. 1914 Spermatogenesis in spiders. I. Zool. Jahrb., Bd. 38.

PAYNe, F. 1908 On the sexual differences of the chromosome groups in Galgulus oculatus. Biol. Bull, vol. 14.

1909 Some new types of chromosome distribution and their relation to sex. Ibid, vol. 16.

1910 The chromosomes of Acholla multispinosa, Ibid., vol. 18. 
Pinney, E. 1908 Organization of the chromosomes in Phrynotettix magnus. Kansas Univ. Sci. Bull., vol. 4.

Robertson, W. R. B. 1915 Chromosome studies. III. Inequalities and deficiencies in homologous chromosomes: their bearing upon synapsis and the loss of unit characters. Jour. Morph., vol. 26.

1916 Taxonomic relationships shown in the chromosomes of the Tettigidae and other subfamilies of the Acrididae: V-shaped chromosomes and chromosome numbers in Acrididae, Locustidae and Gryllidae: chromosomes and variations. Ibid., vol. 27 .

SINETy, R. DE 1901 Recherches sur la biologie et l'anatomie des phasmes. La Cellule, T. 19.

Stevens, N. M. 1906 Studies in spermatogenesis. II. A comparative study of the heterochromosomes in certain species of Coleoptera, Hemiptera and Lepidoptera, etc. Carnegie Inst. Washington, Publ. 36.

1909 Further studies on the chromosomes of the Coleoptera. Jour. Exp. Zoöl., vol. 6.

1910 The chromosomes in the germ cells of Culex. Ibid., vol. 8.

1911 Further studies on heterochromosomes in mosquitoes. Biol. Buil., vol. 20.

Vorvov, D. 1914 Recherches sur la spermatogénèse du Gryllotalpa vulgaris Latr. Arch. Zool. Exper., T. 54.

Wallace, L. B. 1909 The spermatogenesis of Agalena naevia. Biol. Bull, vol. 17 .

Walton, A. C. 1916 Ascaris canis (Werner) and Ascaris felis (Göze). A taxonomic and cytological comparison. Biol. Bull., vol. 31 .

Winkich, D. H. 1916 The spermatogenesis of Phrynotettix magnus, with special reference to synapsis and the individuality of the chromosomes. Bull. Mus. Comp. Zool. Harvard Coll., vol. 60.

1917 Synapsis and chromosome organization in Chorthipus (Stenobothrus) curtipennis and Trimerotropis suffusa (Orthoptera). Jour. Morph., vol. 29.

Wilson, E. B. 1909 Studies on chromosomes, IV. The 'accessory' chromosome in Syromastes and Pyrrhocoris with a comparative review of the types of sexual differences of the chromosome groups. Jour. Exp. Zoöl., vol. 6.

1912 Studies, etc. VIII. Observations on the maturation phenomena in certain Hemiptera and other forms, with considerations on synapsis and reduction. Ibid., vol. 13. 


\section{EXPLANATION OF PLATES}

The figures in all the plates were drawn with the aid of the camera lucida, using in every case a Zeiss hom. imm. $1.5 \mathrm{~mm}$. lens, the oculars varying according to the size of the cell. In figures 1 to 15,22 , and 27 to 35 a Zeiss compens. ocul. No. 12 was used, giving a magnification of 2950 diameters. The same combination was used for figures 16 to 21,23 to $26,39,40$, and 42 to 63 , but they were subsequently enlarged $1 \frac{3}{8}$ diameters to work out details. Figures 36 to 38 and 66 to 86 were made using a Spencer compens. ocul. No. 20, at a magnification of 3600 diameters. Figure 64 was drawn with Spencer ocular 6.

All figures have been reduced $\frac{1}{4}$ in reproduction.

\section{PLATE 1}

EXPLANATION OF FIGURES

1 to 6 Nuclei of secondary spermatogonia showing individualized chromosome $\mathrm{X}$ in different conditions of condensation.

7 The same chromosome drawn from three nuclei belonging to secondary spermatogonia.

8 and 9 Early spermatogonial prophase showing chromatic bands.

10 and 11 Two sections of two spermatogonia showing the orientation of the large chromosomes within the nucleus.

12 Prophase in the spermatogonia of latter generations. 
THE MEIOTIC PHENOMENA IN BLAPS
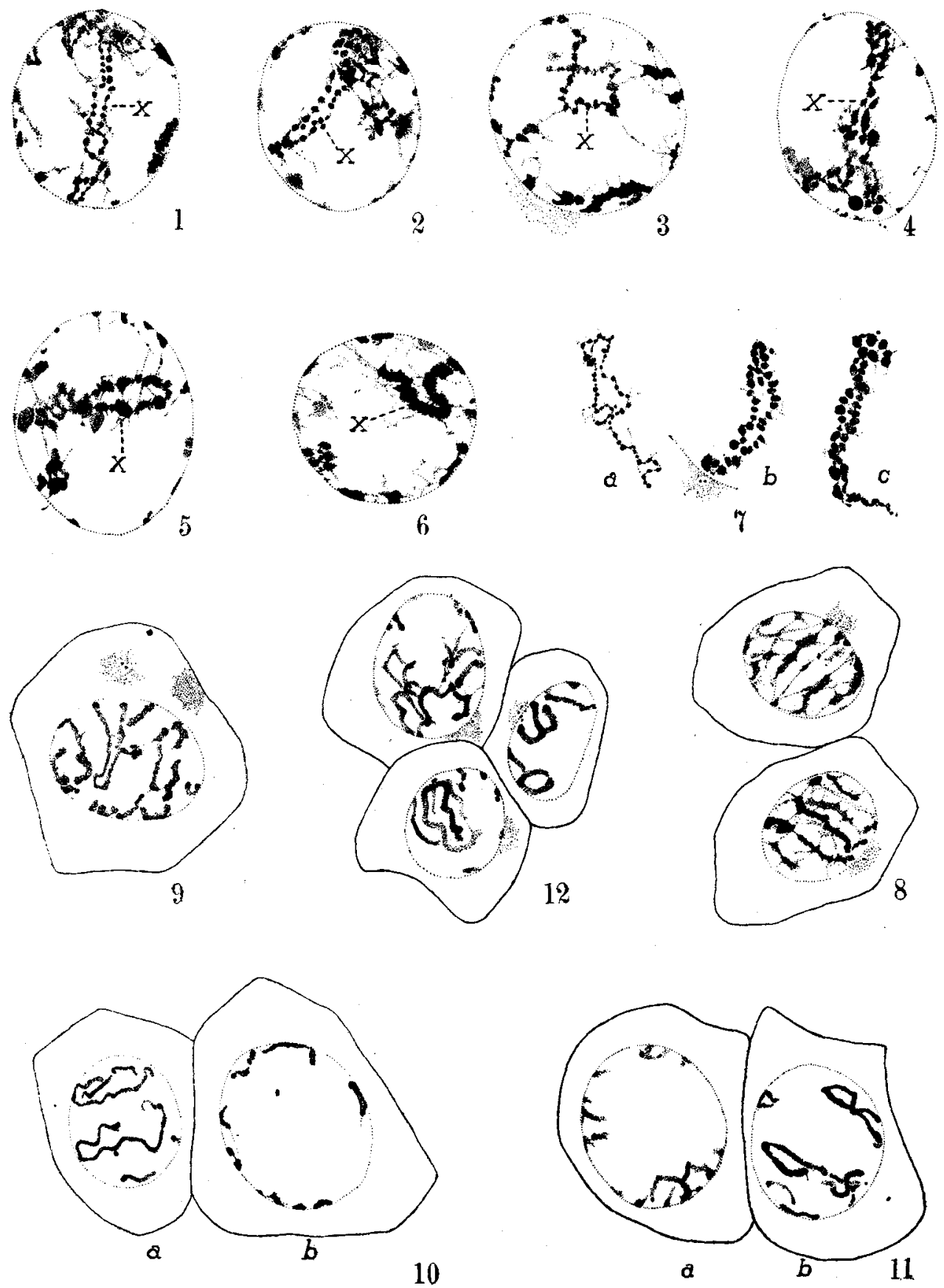

107

JOURNAL OF MORPHOLOGY, VOL. 34, NO. 1 
PLATE 2

EXPLANATION OF FIGURES

13 to 15 . Three stages of the late prophase in the secondary spermatogonia. 16 to 20 Metaphases of secondary spermatogonia showing the X-chromosome $(\mathrm{X})$ and the $\mathrm{M}$-chromosomes (M, $\left.\mathrm{M}^{\prime}\right)$. Figures 16, 19 and 20 belong to the same individual, but to different cellular generations.

21 Large chromosomes drawn from spermatogonia of the same individual to show variation in shape and size. The chromosomes represented in $f$ have been drawn from one of the last spermatogonial mitoses.

22 Metaphase of secondary spermatogonium seen in lateral view; the chromosomes are split lengthwise.

23 to 26 The large chromosomes as seen in the early anaphase of secondary spermatogonia, showing differences in the mode of attachment of the spindle fibers. 


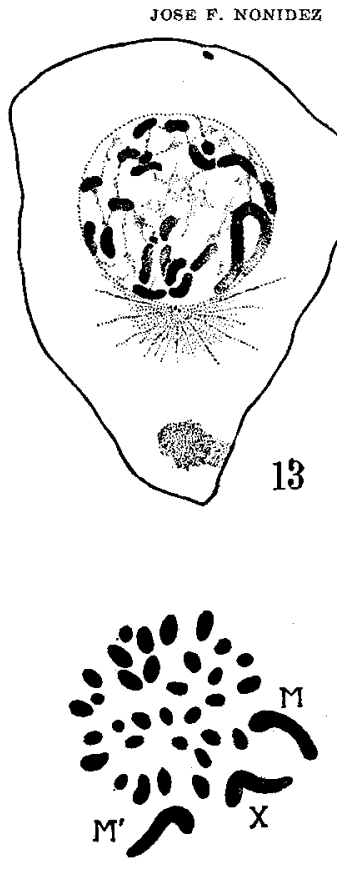

16
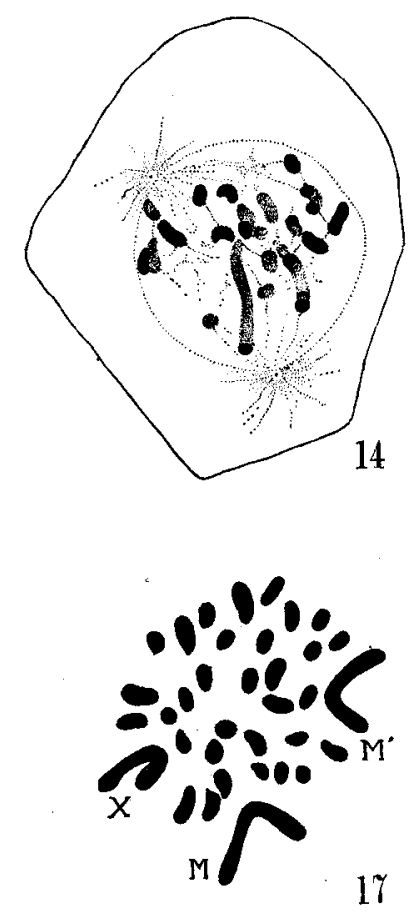
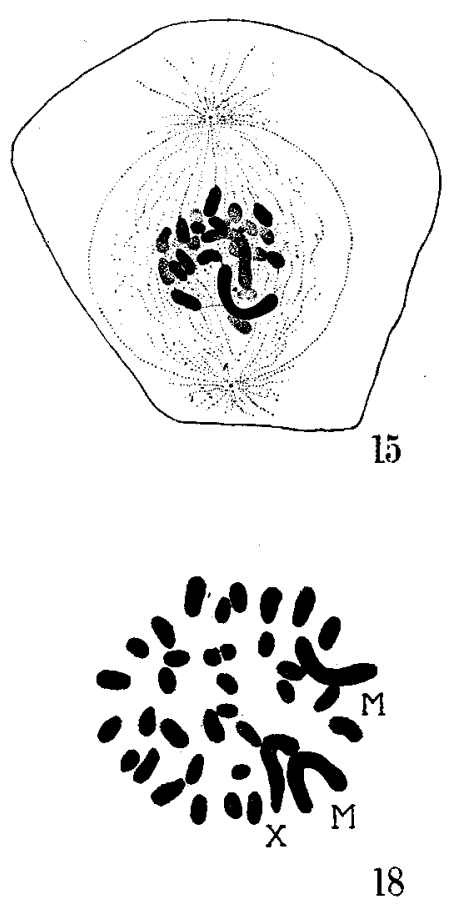

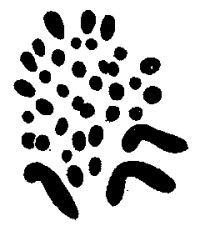

19

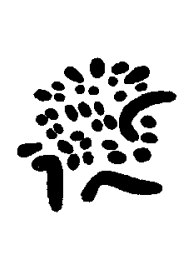

20

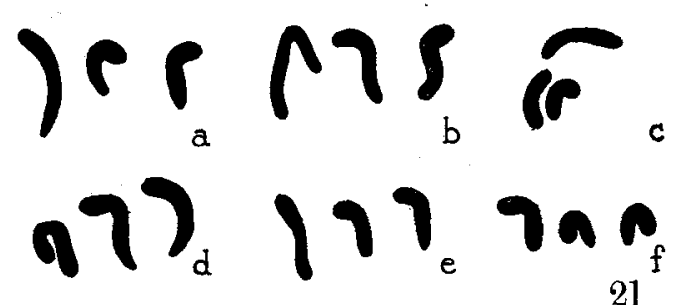

21

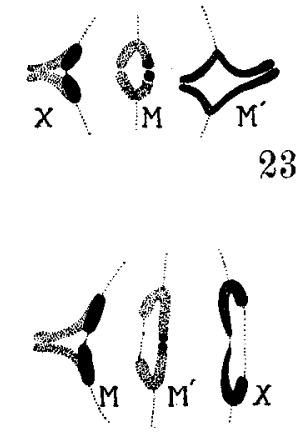

24

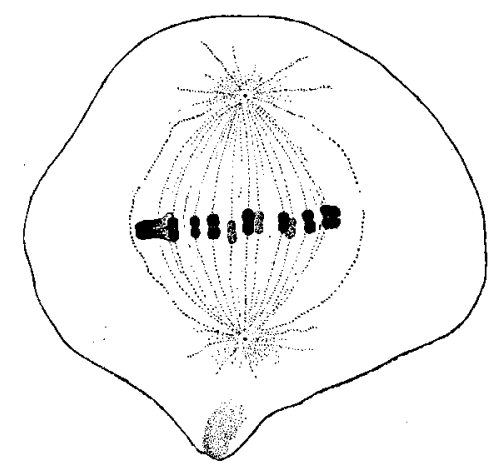

22
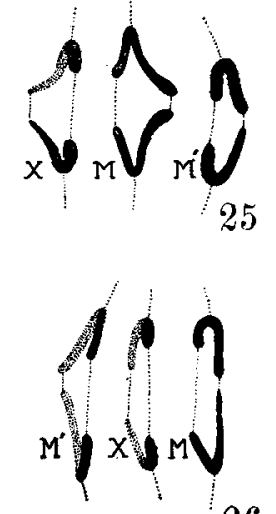


\section{PLATE 3}

EXPLANATION OF FIGURES

27 Early anaphase of a secondary spermatogonium showing differences in the attachment of the spindle fibers.

28 to 31 Later stages in the anaphase of secondary spermatogonia.

32 to 34 Telophases showing migration of the centrosome.

35 Advanced telophase of secondary spermatogonium. The mitosome or spindle remnant is arising and the centrosome (only seen in the upper cell) has completely moved around the nucleus. 
THE MEIOTIC PHENOMENA IN BLAPS

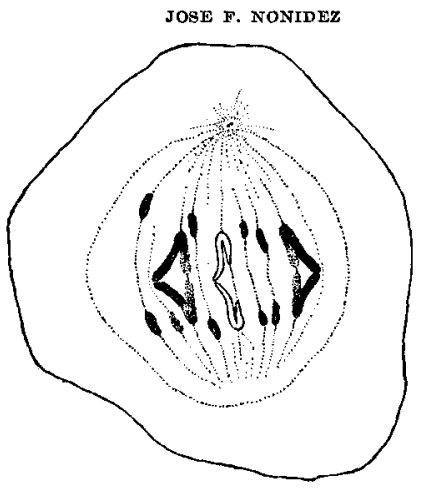

27

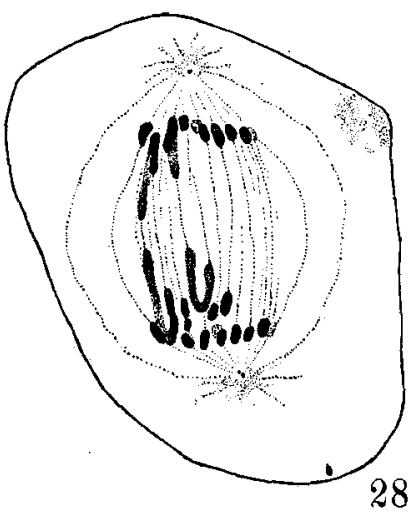

28

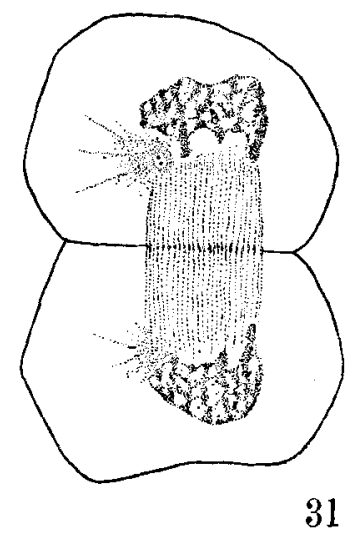

31
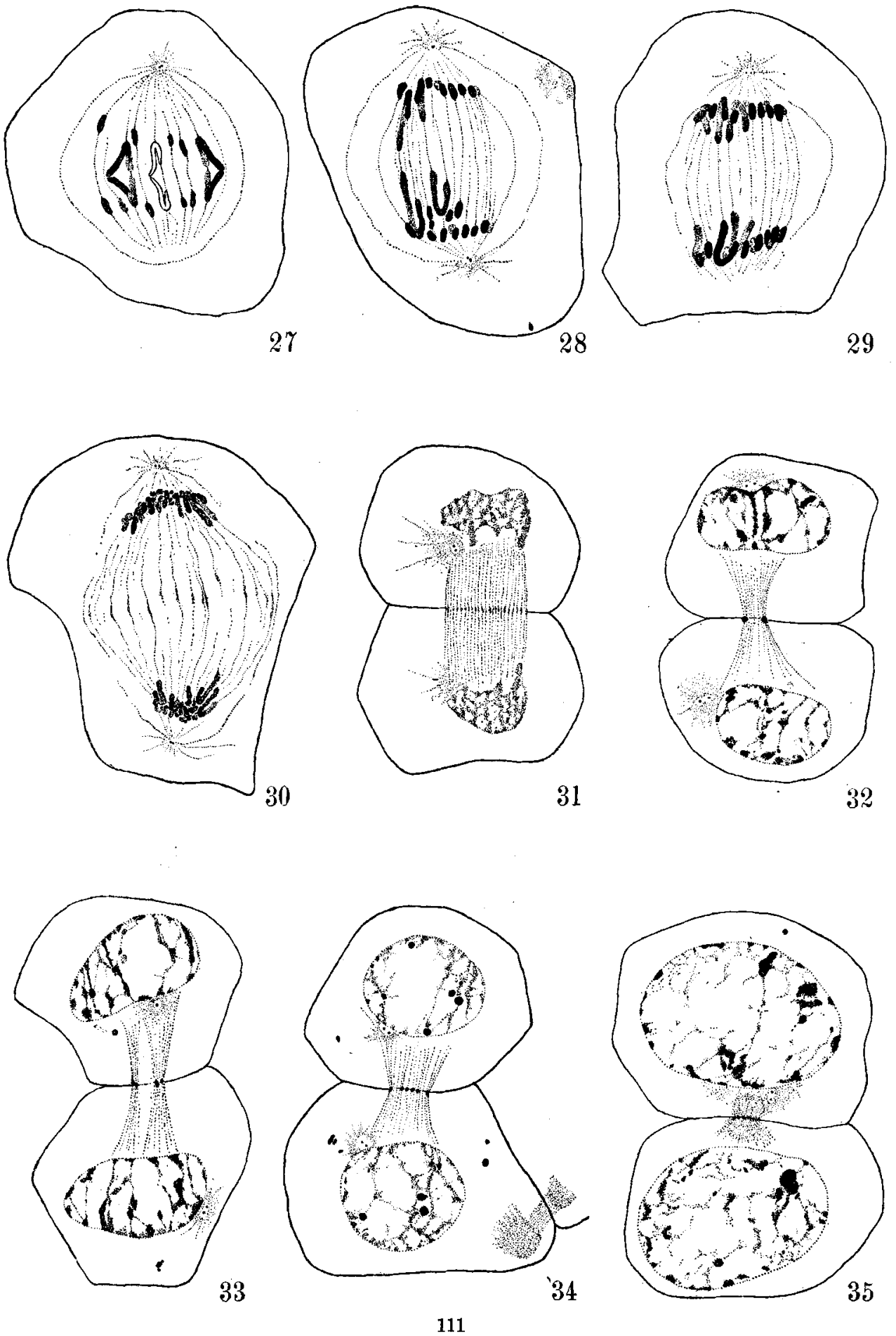


\section{PLATE 4}

\section{FXPLANATION OF FIGURES}

36 Four sections of the nucleus of a spermatocyte during the prophase of the first maturation division, showing the $\mathrm{X}$-complex and fifteen bivalent euchromosomes.

37 Same stage; all the chromosomes represented in the same plane. The condensation of the M-chromosomes is not so advanced as in the preceding figure.

38 Spermatocyte in the early prophase showing splitting of the euchromosomes, which have been disposed in a series in figure 39, according to their degree of condensation.

40 Euchromosomes from different spermatocytes showing differences in the process of splitting. The chromosomes represented in $b$ and $d$ are $\mathrm{Y}$-shaped chromosomes seen-endwise.

$41 \mathrm{X}$-complexes drawn from cells in the early prophase. The M-chromosomes are united directly with each other in $f$, the X-chromosome occupying the end of one of the arms of the V-shaped complex.

42 to 45 Metaphases of the first division in polar view.

46 Four optical sections of a metaphase in lateral view, showing attachment of the spindle fibers in the X-complex.

47 Polar view of a metaphase in which the $\mathrm{X}$-chromosome has failed to condense, appearing as a $U$-shaped body.

48 Three complexes drawn from metaphases. The X-chromosome has failed to condense in $b$. In $c$ a single small chromosome is seen. 

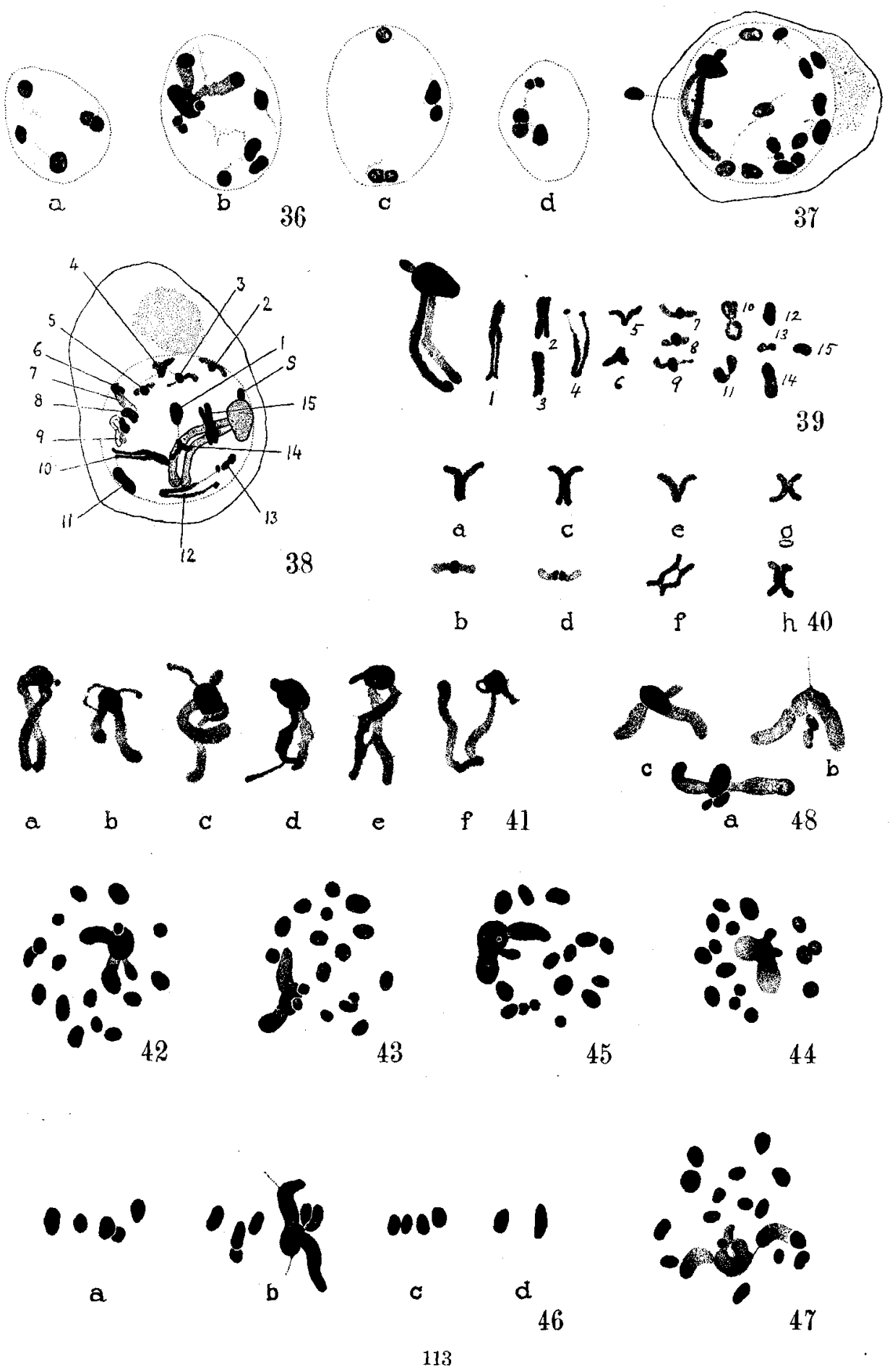


\section{PLATE 5}

\section{EXPLANATION OF FIGURES}

49 to 51 Anaphases of the first maturation mitosis showing the dissociation of the X-complex and the unequal distribution of its components.

52 and 53 Lateral and polar view of the pole of the spindle receiving the $\mathrm{X}$ chromosome. The large chromosomes, which lag behind the euchromosomes, have been represented in the same plane in figure 53.

54 Several stages of the dissociation of the complex showing the progressive appearance of the small chromosomes.

55 Dissociation of the complex. One of the spindle fibers is attached to one or both small chromosomes.

56 Normal metaphase of a secondary spermatocyte with X-chromosome.

57 Metaphase of a secondary spermatocyte with eighteen chromosomes.

58 and 59 Metaphases of secondary spermatocytes without X-chromosome, with sixteen and seventeen chromosomes, respectively.

60 to 63 Lateral views of the anaphases of the secondary spermatocytes, showing the division of the large ehromosomes of the X-complex.

64 Cyst with primary spermatocytes during the resting stage which follows the last spermatogonial mitosis and spermatocytes in the prochromosome stage.

65 Spermatocyte during the resting stage.

66 Formation of the prochromosomes.

67 to 69 Spermatocytes during the prochromosome stage. The X-chromosome is still condensed in figure 67 , while in figures 68 and 69 it appears as a coarse thread. 


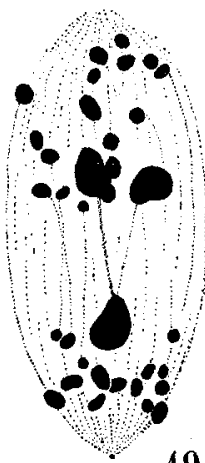

49
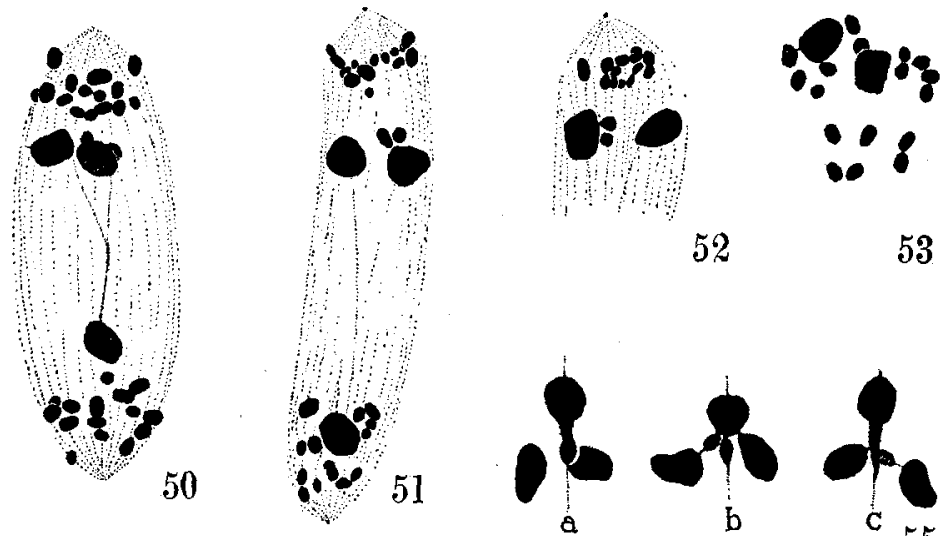

52

53
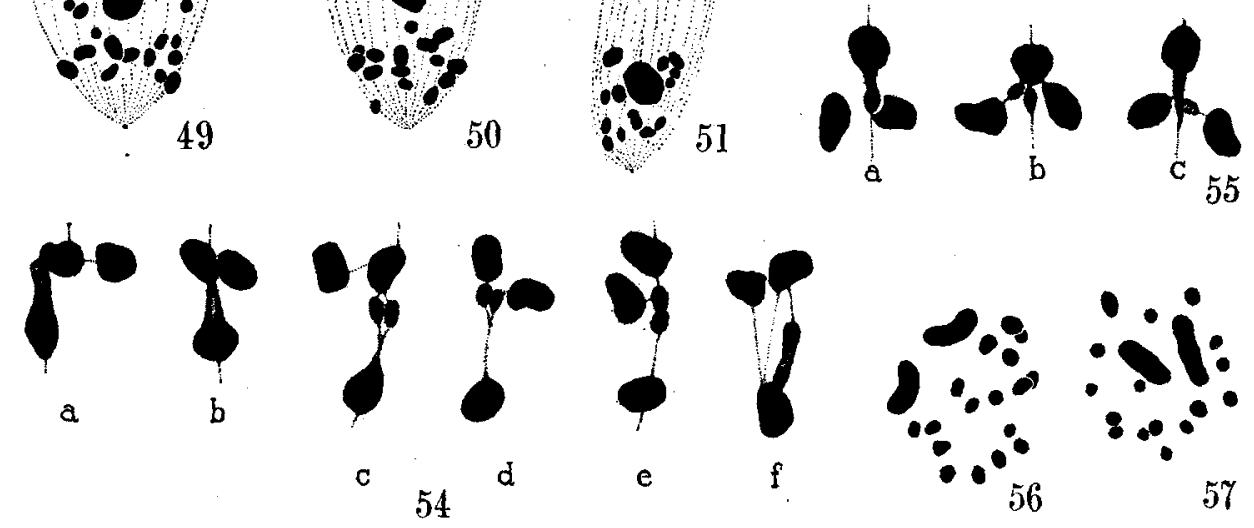

b

55

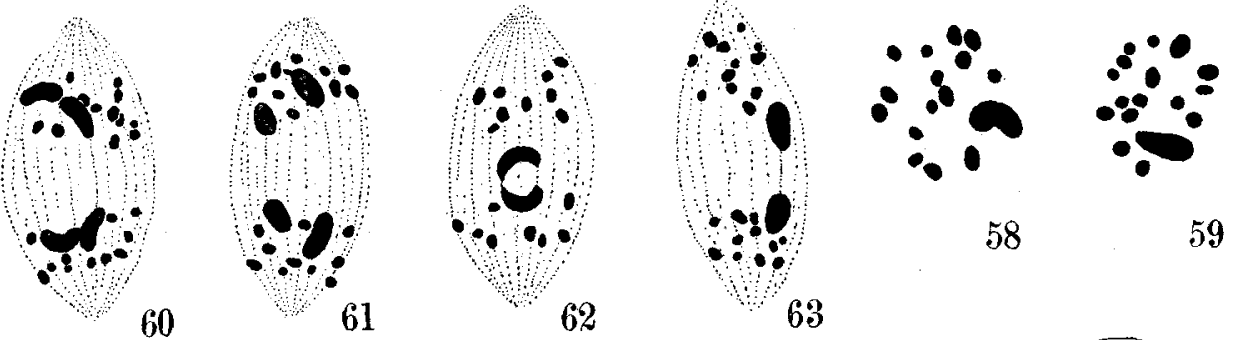

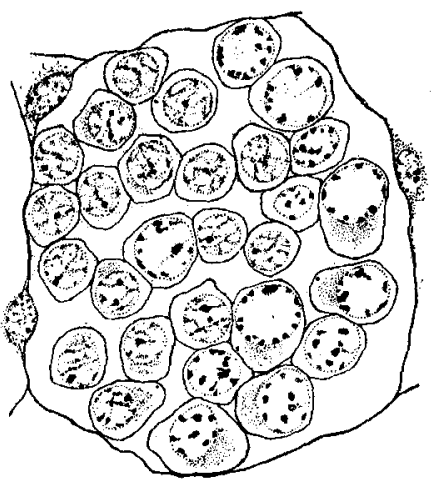

64
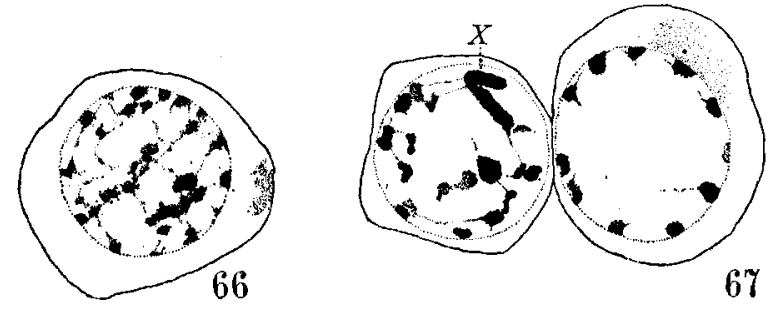

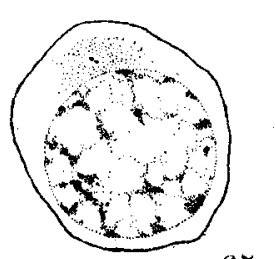

65
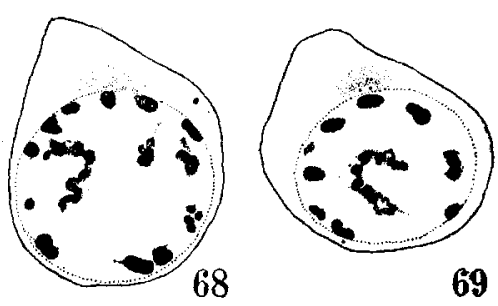


\section{PLATE 6}

\section{EXPLANATION OF FIGURES}

70 Four optical sections of a primary spermatocyte during the prochromosome stage.

71 Beginning of synizesis. The $\mathrm{X}$-complex $(\mathrm{X})$ is already formed and lags behind the euchromosomes.

72 Two cells during synizesis, showing the condensation of all the prochromosomes in the pole of the nucleus nearest to the sphere; in the cell to the left the $\mathrm{X}$-complex has been represented.

73 Polar view of a spermatocyte during synizesis.

$74 \mathrm{X}$-complexes of spermatocytes during synizesis; the $\mathrm{M}$-chromosomes will soon begin to unravel and their outline appears a little ragged.

75 Polar view of a spermatocyte at the beginning of the unraveling stage. The X-complex appears conspicuously.

76 Two details of the unraveling of the $M$-chromosomes.

77 and 78 Leptotene stage, as seen in polar and lateral views of the cells.

79 and 80 Early pachytene stage.

81 to 86 Pachytene stage proper. 

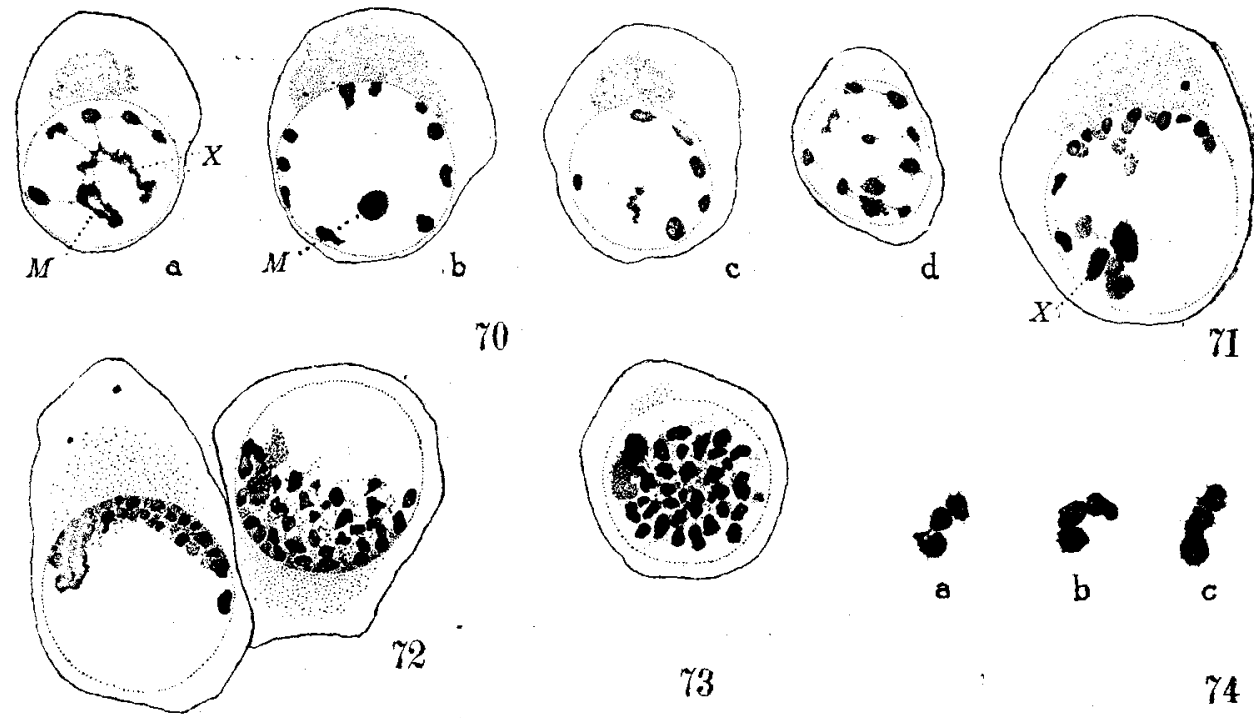

73

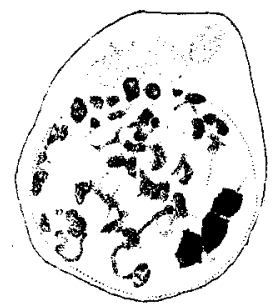

75
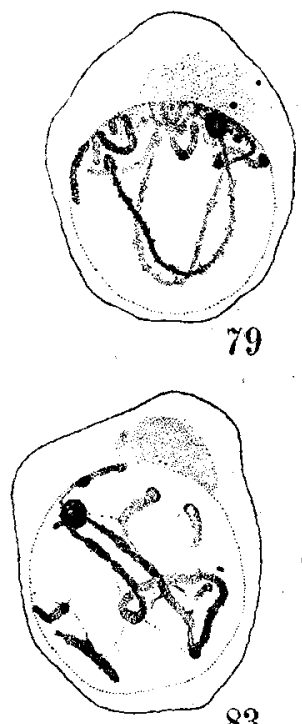

83

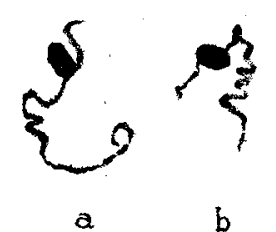

76

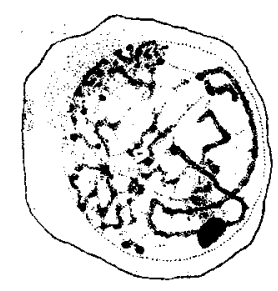

77

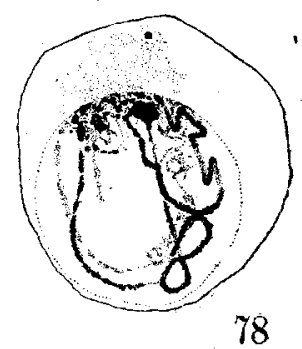

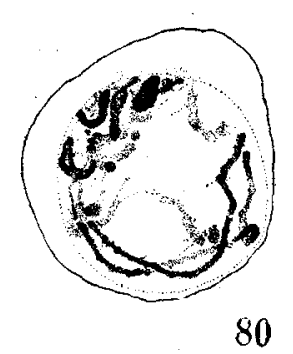
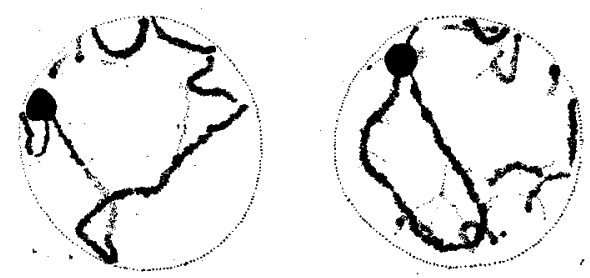

81
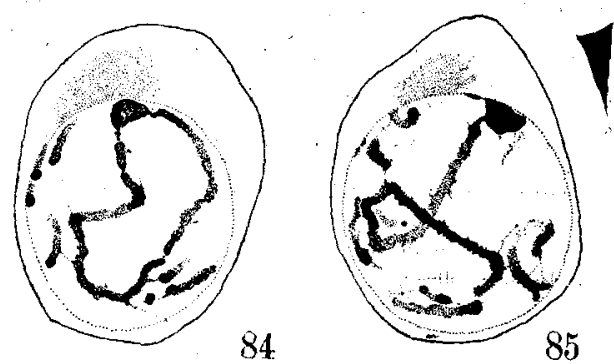

85

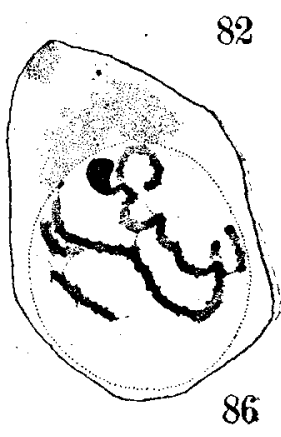

